Complexity Aversion in Risky Choices and Valuations: Moderators and Possible Causes

\author{
Yvonne Oberholzer ${ }^{1}$ \\ Sebastian Olschewski ${ }^{2,3}$ \\ Benjamin Scheibehenne ${ }^{1}$ \\ ${ }^{1}$ Karlsruhe Institute of Technology, Kaiserstraße 89-93, 76133 Karlsruhe, Germany \\ ${ }^{2}$ Department of Psychology, University of Basel, Missionsstrasse 62A, 4055 Basel, \\ Switzerland \\ ${ }^{3}$ Warwick Business School, University of Warwick, Coventry, CV47AL, UK
}

Corresponding author: Yvonne Oberholzer, yvonne.oberholzer@kit.edu

Data, Materials and Preregistration on OSF: https://osf.io/u5an6/

Preprint on PsyArxiv: https://psyarxiv.com/tnvzr

29.06.2022

Word Count: 11,820 


\begin{abstract}
In the age of digitalization and globalization, an abundance of information is available, and our decision environments have become increasingly complex. However, it remains unclear under what circumstances complexity affects risk taking. In two experiments with monetary lotteries (one with a stratified national sample), we investigate behavioral effects and provide a cognitive explanation for the impact of complexity on risk taking. Results show that complexity, defined as the number of possible outcomes of a risky lottery, decreased the choice probability of an option but had a smaller and less consistent effect when evaluating lotteries independently. Importantly, choices of participants who spent more time looking at the complex option were less affected by complexity. A tendency to avoid cognitive effort can explain these effects, as the effort associated with evaluating the complex option can be sidestepped in choice tasks, but less so in valuation tasks. Further, the effect of complexity on valuations was influenced by individual differences in cognitive ability, such that people with higher cognitive ability showed less complexity aversion. Together, the results show that the impact of complexity on risk taking depends on both, decision format and individual differences and we discuss cognitive processes that could give rise to these effects.
\end{abstract} Ability

Keywords: Complexity Aversion, Risk Preferences, Valuation, Choice, Cognitive 


\section{Complexity Aversion in Risky Choices and Valuations: Moderators and Possible Causes}

In the age of globalization and digitalization, the complexity of our decision

environments is ever increasing. Think — for example —of investment decisions, where a large variety of financial products is available that are highly detailed and typically come with several pages of explanations of the payoff structure. Similarly, even for more mundane tasks such as buying a new notebook, consumers have to consider numerous technical attributes that determine the notebook's processing power, comfort of use, battery life and so on. Whereas complexity might be engaging and informative for some individuals, others might struggle to keep up with the flood of information. In any case, to help people make better decisions, it is important to understand how complexity affects their behavior. In our study, we contribute to this understanding by investigating the influence of complexity on decision making by means of risky lotteries, which allow for simple and clean manipulation of complexity based on number of attributes (outcomes).

Previous research has suggested that complexity can lead to deference or deflection of choice (Dhar, 1997a, 1997b; Tversky \& Shafir, 1992), increased preference for the status quo (Boxall et al., 2009; Frank \& Lamiraud, 2009), or decreasing engagement with the decision problem (Blaufus \& Ortlieb, 2009). While most of these effects are widely known, the effects on choice deferral have proven difficult to replicate (Evangelidis et al., 2022). Beyond this, studies on valuations and choices under risk and uncertainty have reported that more complex risky gambles, those with higher numbers of outcomes, were chosen less often or were valued less than simple ones (Huck \& Weizsäcker, 1999; Mador et al., 2000; Sonsino et al., 2002). This behavior has been called complexity aversion (see Mador et al., 2000; Sonsino et al., 2002). Such complexity aversion can lead to suboptimal decisions because people would be willing to choose options with lower expected value or expected utility to avoid complexity. Other researchers, however, found complexity neutrality in risky valuations (Bruce \& 
Johnson, 1996). Yet other findings suggest that complexity aversion occurs only in some of the population because of individual differences (Moffatt et al., 2015).

In addition to questions regarding the existence of complexity aversion, little is known about the underlying reasons and the cognitive mechanisms that could explain when and why people avoid or undervalue complex risky options. The goal of this article is to investigate this. In the following, we review the existing literature on this question and then derive predictions from it. In particular, we focus on differences between valuation and choices and on individual differences in motivation and cognitive ability.

\section{Differences Between Valuation and Choice}

Complexity aversion has been observed mostly in pairwise choices between simple and complex options (e.g., Huck \& Weizsäcker, 1999; Moffatt et al., 2015; Sonsino et al., 2002). There is less evidence, in contrast, for a systematic negative effect of complexity in valuation tasks: Whereas individual differences in valuations of simple and complex options have been reported for intertemporal risky gambles (Mador et al., 2000), no such effect has been found for pure (not intertemporal) risky gambles (Bruce \& Johnson, 1996). Qualitative differences in preferences due to presentation formats or elicitation methods in general and between valuations and choices in particular are well documented in the literature (e.g., Slovic \& Lichtenstein, 1983; Tversky et al., 1990). In the following, we will outline possible reasons for the difference between valuation and choice.

First, when choosing among options that differ in complexity, selecting the simpler alternative could be a strategy to avoid the exertion of cognitive effort needed to evaluate the more numerous outcomes of the complex option in the first place. This explanation is corroborated by previous research showing that people tend to avoid activities that demand the investment of cognitive effort (e.g., Inzlicht et al., 2018; Kool et al., 2010; Stanovich, 2018). In line with this “cognitive miser" account, participants in an experiment by

Westbrook et al. (2013) willingly forwent a monetary reward if they had the option to perform 
a task that was less cognitively demanding than another, a behavior called cognitive effort discounting. In the context of complexity aversion, this explanation applies to choice tasks more than to valuation tasks because the evaluation of an option is much harder to avoid in a valuation task. Hence it predicts more pronounced effects of complexity aversion for choice tasks. However, complexity aversion in valuation is still plausible if people discount options because they dislike the cognitive effort associated with them.

Second, complexity aversion in choices could also be driven by preference variability (Mador et al., 2000; Sonsino et al., 2002): If people have difficulties evaluating complex gambles, their evaluations will be noisier and more error prone. If this noise is unsystematic, it will not translate to systematically lower valuations directly, but it can trigger less consistent (i.e., less utility-maximizing) behavior. In the extreme case, excessive noise will lead to choice proportions approaching 50:50 for pairwise choices. In situations where the complex gamble is more attractive in terms of expected value or variance (as, for example, in Huck \& Weizsäcker, 1999; Sonsino et al., 2002), a complexity-induced decrease in consistency could hence be interpreted as complexity aversion (see also Olschewski et al., 2018). We refer to this as the noise hypothesis.

\section{Influence of Numerical Cognition}

Evaluating risky gambles typically requires the perception and integration of numerical information to grasp payoffs and probabilities. As mentioned above, this process will be more error prone for complex lotteries. Presumably, decision makers do not like this imprecision in the first place (Burks et al., 2009). The resulting errors also depict an additional (epistemic) risk above and beyond the (aleatory) risk due to the variance of the gamble (Fox \& Ülkümen, 2011). Namely, the risk that the estimates of potential outcomes is imprecise and thus does not reflect the true underlying reward structure. To the extent that risk-averse decisionmakers are aware of their increased error probability, complex gambles should receive lower valuations (see also Andersson et al., 2016). 
Besides this second-order risk aversion, research on numerical cognition has further suggested that humans' number sense maps onto a compressed scale (e.g., Dehaene, 1992, 2011; Schley \& Peters, 2014). This compression has been observed predominantly in nonsymbolic number perception, but it has been hypothesized that compression also applies to symbolic numbers (e.g., Dehaene, 1992). In line with this, previous research found that summary statistics of number sequences (i.e., sum, mean, expected value) are systematically underestimated in decisions from experience (Olschewski et al., 2021; Scheibehenne, 2019). Presumably, these findings would generalize to decisions from description in which there is also numerical information that needs to be processed. Additionally, it has been hypothesized that there are two representations of symbolic numbers, one intuitive and compressed and the other learned and linear (e.g., Izard \& Dehaene, 2008; Siegler \& Opfer, 2003). To the extent that decision makers adopt the more compressed intuitive representation to mitigate complexity, complex gambles would be valued less because their expected value is underestimated.

\section{Cognitive Ability as a Moderator}

Irrespective of possible differences between valuation and choice, the perceived complexity of an option eventually is subjective and hence may differ between individuals. In line with this, past research found that complexity aversion is subject to individual differences (e.g., Moffatt et al., 2015; Westbrook et al., 2013; Zilker et al., 2020). One reason for these individual differences could be that people with higher cognitive abilities are less affected by complexity in the first place because they can still assess these gambles with reasonable accuracy. Likewise, if people with high cognitive ability do not need to exert as much effort to assess complex lotteries, they might discount them less than people with low cognitive ability. In support of this, past research found individual differences in the above-mentioned tendency to avoid cognitive effort (e.g., Inzlicht et al., 2018; Sandra \& Otto, 2018).

Furthermore, Westbrook et al. (2013) found more discounting of cognitive effort in older 
compared to younger adults. This age effect could be due to age-specific changes, such as recruiting of more neural resources at lower levels of cognitive load as a compensation mechanism (e.g., Grady, 2012; Schneider-Garces et al., 2010) or a decline of fluid intelligence (e.g., Bopp \& Verhaeghen, 2005; Horn \& Cattell, 1967). Taken together, this suggests that cognitive ability moderates complexity aversion in risky choices and possibly also in valuations.

\section{The Current Study}

To investigate the predictions of the different theoretical accounts and cognitive mechanisms behind complexity aversion we conducted two behavioral experiments (see Table 1 for an overview).

\section{Table 1}

Research Questions Addressed in the Two Experiments

\begin{tabular}{lll}
\hline Research Question & Addressed in & Findings \\
\hline $\begin{array}{l}\text { Is there a behavioral effect of } \\
\text { complexity aversion? }\end{array}$ & Exp 1\& 2 & $\begin{array}{l}\text { Yes, in choices. Dependent on } \\
\text { cognitive ability in valuations. }\end{array}$ \\
$\begin{array}{l}\text { Is it caused by a systematic } \\
\text { bias or by unsystematic noise? }\end{array}$ & Exp 1 (\& 2) & $\begin{array}{l}\text { Both. Evidence for a systematic and an } \\
\text { unsystematic effect. }\end{array}$ \\
$\begin{array}{l}\text { Is the systematic effect a pre- } \\
\text { ference or a perceptual bias? }\end{array}$ & Exp 1 & $\begin{array}{l}\text { Likely a pure preference. No evidence } \\
\text { for perceptual bias or dislike of noisy } \\
\text { perception. }\end{array}$ \\
$\begin{array}{l}\text { Is the preference dependent on } \\
\text { the dislike of cognitive effort? }\end{array}$ & Exp 2 & $\begin{array}{l}\text { Yes, likely. One process measure of } \\
\text { cognitive effort (looking time pro- } \\
\text { portion) is a credible predictor of the } \\
\text { effect, however, another (speed) is not. }\end{array}$ \\
$\begin{array}{l}\text { Is individual cognitive ability a } \\
\text { moderator of the effect of }\end{array}$ & Exp 2 & $\begin{array}{l}\text { Yes, cognitive ability moderates } \\
\text { complexity? }\end{array}$ \\
\hline
\end{tabular}


Note. Exp: Experiment. Regarding the second research question, Experiment 1 was designed to test it and found evidence in support of complexity increasing unsystematic noise. While Experiment 2 was not specifically designed to test the question, it also examined the possibility of a systematic effect and found evidence in support for it.

In the first experiment, we investigated the effect of complexity on valuations of risky lotteries, the format for which previous results were least consistent. We further employed a mean estimation task. Because preferences for complexity or risk should not affect mean estimations, this task allowed us to examine the effect of complexity on a perceptual level. To increase generalizability, we employed a broad range of stimuli while controlling for variance, skewness, and expected value. Following-up on this first experiment, we conducted a second experiment to examine whether complexity has a stronger effect on binary choices than on valuations. To examine whether a possible difference between the elicitation formats could be due to the avoidance of cognitive effort in binary choices, we further implemented two process measures of cognitive effort, looking time proportion (i.e., time spent looking at the complex option divided by time spent looking at the simple option) and decision speed. To examine cognitive ability as a potential moderator, we assessed participants' cognitive ability and recruited a stratified national sample (age, gender, and ethnicity) of the U.S. population. As in Experiment 1, we again employed a broad range of stimuli while controlling for variance, skewness, and expected value. Taken together, the two experiments explored the effect of complexity aversion in valuation and choice, investigated different underlying cognitive mechanisms, and assessed the moderating role of cognitive ability on the effect.

\section{Experiment 1}

\section{Method}

\section{Material}


Participants in the experiment were asked to evaluate 24 two-outcome lotteries presented on a computer screen. To each simple lottery, we matched a complex lottery with seven outcomes that had the same expected value, standard deviation, and skewness. We included two levels of expected value (low: 70-90, and high: 110-130), two levels of variance (SD: low: 5-20, and high: 35-50), and three levels of skewness (left: $-2.25-0.75$, none: $-0.75-0.75$, and right: $0.75-2.25$ ). The currency of the outcomes (e.g., £75 or \$75) was not specified to keep the estimation and valuation task comparable. The experiment used a within-subject design with one minor adjustment: To avoid a bias due to the changing range and the maximum and minimum outcome associated therewith, we implemented two sets of complex lotteries as an additional between-subjects control factor. The range of outcomes needed to be implemented as a between-subjects variable because keeping variance and skewness constant while increasing the number of outcomes inevitably increases the range. Consequently, in one set, the variance was kept constant but the range increased, and in the other set the range was kept constant, but the variance decreased. Participants were randomly assigned to one of the two control conditions.

The experiment consisted of two blocks that were presented in randomized order. In the estimation block, participants had to estimate the mean of the presented lotteries. In the valuation block, they had to indicate their minimum selling price for the lotteries presented. Participants indicated their answer by entering a number into an input field on the screen. To measure participants' insights into their estimation uncertainty, we asked them about their confidence after each estimation as follows: "How sure are you that your estimate is within $10 \%$ of the actual mean?" Answers were recorded on a 7-point Likert scale ranging from not sure at all to completely sure. As an example, Figure 1 shows a screenshot of the estimation and valuation tasks respectively.

\section{Figure 1}


Task Examples for Estimation (Left) and Valuation (Right)

What is your estimation of the mean of this lottery?

23 with $29 \%$

114 with $71 \%$

114 with $71 \%$

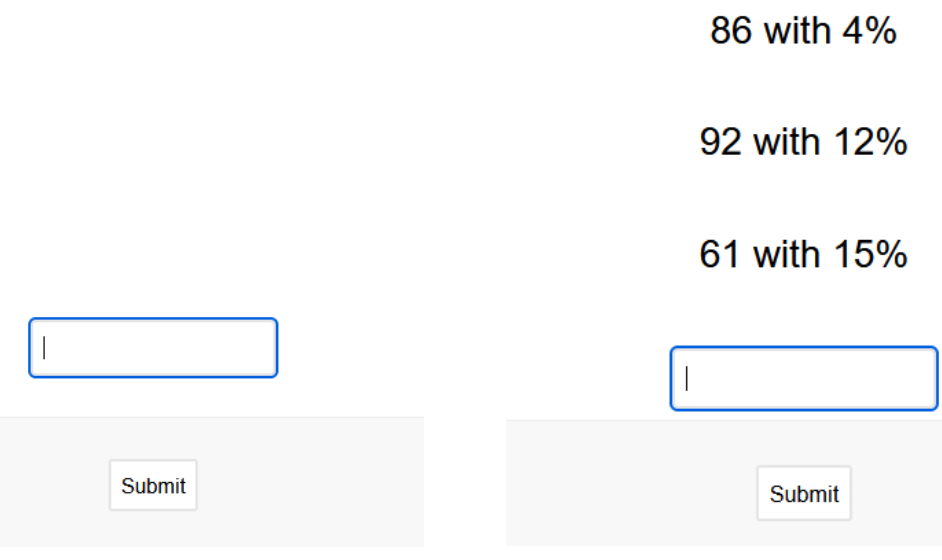

Note. The participants could enter a number via the keyboard in both the estimation (left) and valuation (right) task. In this example, a simple lottery with two outcomes is evaluated in the estimation task and a complex lottery with seven outcomes is evaluated in the valuation task. The participants' answers were saved after clicking on the "Submit" button. There was no time limit for the task.

The order of the lotteries within each block and the order of the outcomes within each lottery were randomized. To assess participants' understanding of the task, we asked them to repeat the goal of the task in their own words after reading the instructions (before the task). Additionally, we asked the participants to select which answers were considered "logically valid" in a multiple-choice question. In the instructions, we explained that answers below the lowest outcome and answers above the highest outcome of a lottery were not considered logically valid, so the question was implemented as an instruction check. Apart from 
participants' answers, we assessed reaction times in all elements of the experiment. At the end of the experiment, we assessed demographics (age, gender, and country of origin) and asked participants whether they had completed the experiment in good faith. Participants were encouraged to answer this question truthfully and were additionally reminded that their answer would have no consequence for them or their probability of winning the raffle. To analyze the data, Bayesian methods were used when available. Inferences were drawn on the basis of credible intervals, Bayes factors (BFs), confidence intervals, and $p$ values.

The experiment was preregistered and the preregistration, the experiment, the set of lotteries, the data, and the analysis script can be found on the Open Science Framework (OSF, https://osf.io/jpsur; https://osf.io/u5an6/). Deviations from the preregistration and their respective justifications (e.g., accounting for repeated measures in data) are reported in the text or in Appendix A.

\section{Participants and Procedure}

On the basis of previous research (Huck \& Weizsäcker, 1999; Mador et al., 2000; Sonsino et al., 2002), we estimated the effect of complexity aversion to be small to medium. Given this, we conducted a power analysis using the pwr (Champely, 2020) package in R (R Core Team, 2020), revealing a target sample size of 147 for a power of $95 \%(\alpha=.05, d=0.3$, two-sided) based on a paired $t$ test intended to compare evaluations of single and complex lotteries. Informed by this, we tested a convenience sample of 131 bachelor's students in economics and management at the University of Geneva who participated in exchange for course credit and the possibility to win CHF 100 in a raffle depending on their performance. In particular, the estimation task was incentivized based on accuracy, with the students winning more points when their estimate of the mean was accurate. The valuation task was incentivized on the basis of a Becker-DeGroot-Marschak (BDM) auction (Becker et al., 1964), with the offer being drawn between the minimum and the maximum outcome of the lottery. This procedure guarantees that it is incentive compatible for participants to state the 
true monetary equivalent of their subjective utility for a given lottery. Both incentivation procedures were explained to the participants based on an example task in which detailed outcomes were displayed (see also supplementary materials). At the end of the study, one lottery for each task was drawn for the points calculation. There was no deception involved in the experiment and all information provided to the participants was truthful to the authors' best knowledge.

Data from 10 participants were excluded for the following (preregistered) reasons: participant requested exclusion (three), not following instructions by writing calculations down or restarting the experiment (two), completing the experiment too fast ( $1 / 4$ of mean time) or too slow (twice mean time; two), and not understanding the instructions in both tasks (three). Additionally, task-specific data were removed for any participant not understanding the instructions in the estimation task (seven) and for any not understanding the instructions in the valuation task (14). As the participants took a bit longer than expected to complete the experiment, the exclusion criteria for the time spent on the experiment were slightly adjusted from the preregistration, in which we specified that we would set the cut-off based on the expected time ( $25 \mathrm{~min}$ ). Furthermore, the participants did extremely poorly on the multiplechoice question designed as an instruction check, with only seven correctly selecting all three "logically valid" answers of the six alternatives presented. The vast majority of the students identified only the most probable outcome that was closest to the expected value instead of selecting all possible answers. Therefore, we concluded that the question was not asked clearly and decided not to apply this exclusion criterion as preregistered. Instead, we inverted it, excluding the answers of participants who gave an unmistakably wrong answer and chose an outcome below the minimum or above the maximum. This led to the exclusion of an additional 13 participants. While this might seem to indicate that the data quality was poor, the participants answers in the estimation (and valuation) task were highly precise, indicating the fault lied with the instruction check and not with participants' negligence. Additionally, 
we did not apply the exclusion criterion intended to detect calculator use in participants (over $95 \%$ accuracy in estimation or valuation), as we conducted the experiment in a laboratory and could therefore control for people using external aids. The remaining data set included data from 108 participants.

The experiment was built in the lab.js editor (Henninger et al., 2019) and distributed with JATOS software (Lange et al., 2015). The participants completed the experiment in a behavioral laboratory situated at the University of Geneva in April 2019. The average age of the final sample was 21.62 years $(M d n=21$ years, $S D=1.79)$. Fifty-five of the participants were female and 53 were male. The experiment lasted $32.1 \mathrm{~min}$ on average $(M d n=29.52$ $\min , S D=12.27)$

\section{Results}

We removed individual data points when participants' answers were out of bounds (above the maximum or below the minimum of the outcomes presented in the lottery), which led to an exclusion of $6 \%$ of the data in the estimation task and $4 \%$ of the data in the valuation task. Additionally, we removed data points if the participants took longer than $2 S D$ s to give an answer (4\% in the estimation task, $5 \%$ in the valuation task), or if they took less than $2 \mathrm{~s}$ to give an answer $(0.4 \%$ in valuation task, no data points in estimation task).

\section{Valuation and Estimation}

Figure 2 shows the individual mean valuations and estimations for simple and complex lotteries (aggregated). A one-sided paired $t$ test on this data revealed that participants did not value complex lotteries $\left(M_{\mathrm{c}}=97.68, S D_{\mathrm{c}}=9.03\right)$ less than simple lotteries $\left(M_{\mathrm{s}}=\right.$ 98.19, $\left.S D_{\mathrm{s}}=8.56\right), B F_{0-}=4.86, t(97)=0.67, p=0.25$, on average. This represents evidence against a systematic, negative influence of complexity on valuations.

\section{Figure 2}


A

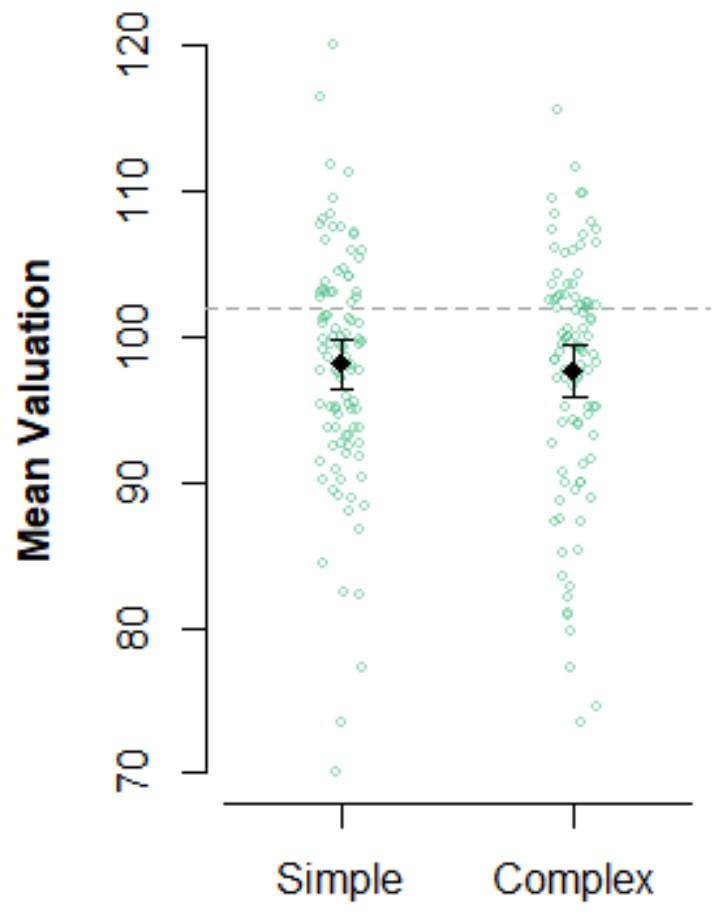

Lottery
B

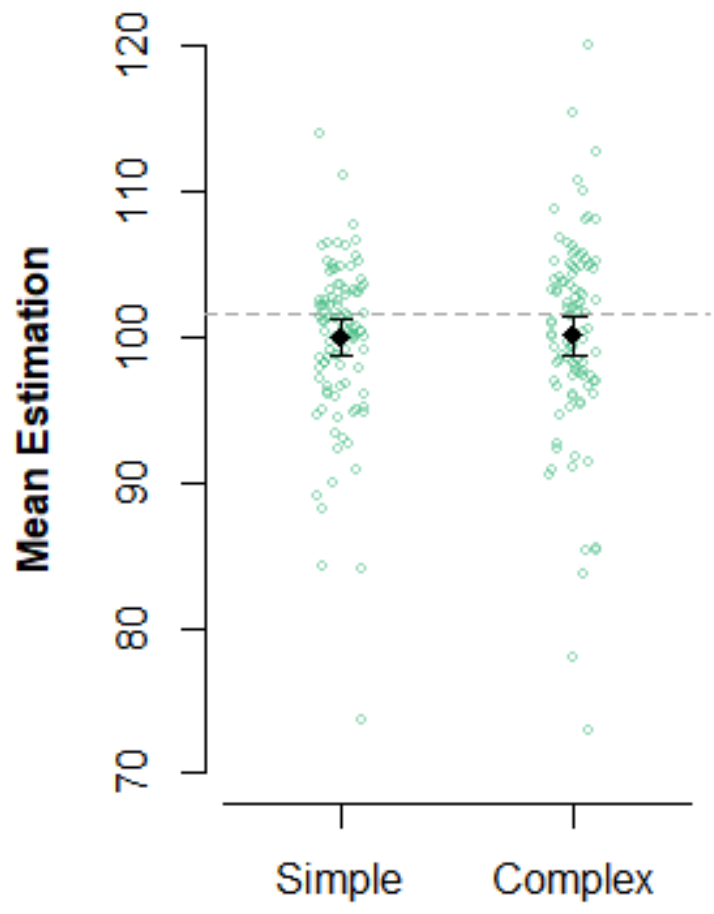

Lottery

Note. The dashed lines indicate the overall mean of the experienced sequences for valuations $\left(M_{\mathrm{v}}=101.55\right)$ and estimations $\left(M_{\mathrm{e}}=101.53\right)$. Error bars denote $95 \%$ confidence intervals based on standard errors. The figure shows no aggregated effect of complexity in either task, except slightly higher variance in the estimation of complex lotteries.

Similarly, participants did not estimate complex lotteries $\left(M_{\mathrm{c}}=100.11, S D_{\mathrm{c}}=6.98\right)$ to have a lower mean than simple lotteries $\left(M_{\mathrm{s}}=99.98, S D_{\mathrm{s}}=6.13\right), B F_{0-}=10.95, t(100)=-$ $0.25, p=.60$, on average. This represents evidence against a systematic, negative influence of complexity on the perceptual level. These results for valuation and estimation were confirmed by Bayesian multilevel models with participant random intercepts and random slopes for each factor to allow for individual differences using the brms package (Bürkner, 2018) in $R$ ( $R$ Core Team, 2020) and default priors (see Table 2 for the model summary). ${ }^{1}$ Controlling for

${ }^{1}$ We preregistered to include the factor estimation (matched) in the regression for valuation. However, as there was high collinearity between the factor estimation and expected value, $r(2,384)=.91, p<.001$, we dropped the factor estimation from the model and conducted a separate analysis of it instead. 
the specific lottery characteristics, we further found that right skewness, low variance, and higher expected value led to higher valuations. Similarly, the multilevel model for estimation valuations confirmed that complexity did not have a systematic, negative effect on estimations (see Table 2). Estimations were higher for right skewed, and lotteries with higher expected value. Noteworthily, a negative effect of variance (i.e., risk aversion) was only present in valuations.

\section{Table 2}

Beta Estimates for Estimation and Valuation

\begin{tabular}{lll}
\hline Factor & Estimation & Valuation \\
\hline Intercept & 0.37 & 2.05 \\
& $(1.04)$ & $(1.28)$ \\
Complexity & 0.12 & -0.89 \\
& $(0.49)$ & $(0.63)$ \\
Skewness & $1.19^{\mathrm{a}}$ & $2.62^{\mathrm{a}}$ \\
& $(0.32)$ & $(0.43)$ \\
SD & 0.01 & $-0.14^{\mathrm{a}}$ \\
& $(0.02)$ & $(0.03)$ \\
EV & $0.98^{\mathrm{a}}$ & $0.98^{\mathrm{a}}$ \\
& $(0.01)$ & $(0.01)$
\end{tabular}

Note. Estimation errors are reported in parentheses. Complexity: Simple $=0$ and complex $=1$. $\mathrm{SD}=$ Standard deviation; $\mathrm{EV}=$ expected value

${ }^{\text {a }}$ Indicates a beta estimate for which zero is not contained in the $95 \%$ credible interval.

Addressing the correspondence between the perceptual level (estimation) and the preferential level (valuation), the multilevel model including the factor estimation only was able to predict the corresponding valuation well. However, this prediction was less precise than the prediction of the expected value of the lottery, $\beta=0.84,95 \%$ confidence interval $(\mathrm{CI})$ $[0.80,0.87]$. Although estimation influenced valuation, there was no evidence of a systematic 
perceptual bias being propagated to valuations because we found evidence against a systematic influence of complexity on both the perceptual and the preferential level.

\section{Confidence}

To investigate if participants perceived their estimations for complex lotteries as less precise, we aggregated confidence ratings within participants and conducted a one-sided paired Wilcoxon signed-rank test. The participants indicated higher confidence for their estimates of simple lotteries $\left(M d n_{\mathrm{s}}=4.59\right)$ compared to complex lotteries $\left(M d n_{\mathrm{c}}=3.84\right), V=$ $4,307, p<.001$, on average. This suggests that participants were aware of the uncertainty being caused by complexity. However, as there was no systematic difference in valuations between complex and simple lotteries, this decrease in confidence apparently did not affect valuations.

\section{Control Variable}

The analyses mentioned above were additionally repeated separately for the betweensubject factors of constant variance or constant range (see Appendix B for details). Apart from a slight difference in the influence of skewness and variance in the estimation condition, there was no qualitative difference in the results, meaning our conclusions remain unaffected by this control variable.

\section{Unsystematic Deviation}

While the previously assessed confidence ratings for estimations clearly differed for complex and simple lotteries, a one-sided paired $t$ test assessing if participants gave more variable valuations to complex lotteries remained inconclusive $\left(M_{\mathrm{c}}=26.43, S D=4.56, M_{\mathrm{s}}=\right.$ $25.76, S D=3.94), B F_{-0}=0.46, t(95)=-1.30, p=.10$. Analogously, the test for unsystematic deviation in estimations was statistically significant, but the BF in favor of the alternative hypothesis remained inconclusive as well $\left(M_{\mathrm{c}}=25.40, S D=4.26, M_{\mathrm{s}}=24.40, S D=2.91\right)$, $B F_{-0}=1.60, t(98)=-2.05, p=.02$. 
To shed more light on the relationship between complexity and unsystematic noise on the task level, we conducted a (pre-registered) multilevel analysis. For this, absolute deviations from the actual expected value were analyzed in a Bayesian multilevel regression model using default priors, implemented with participant random intercepts and random slopes for each factor to allow for individual differences. ${ }^{2}$ The results, summarized in Table 2 , reveal that higher complexity, deviation in estimation (matched), variance, and expected value led to higher deviation in valuations. Similarly, the model for estimations revealed that higher complexity, and variance led to higher deviations in estimation. To illustrate, all else being equal (and not considering the deviation propagated through the log-transformed absolute estimation of the same lottery), the absolute deviation for valuations was $\exp (0.27)=31 \%$, and the absolute deviation for estimations was $\exp (0.43)=54 \%$ higher for complex lotteries than simple lotteries. ${ }^{3}$ Relating back to the inconclusive findings of the $t$-test of individual valuation and estimation variability, the multilevel model was likely more powerful to detect the effect of complexity. Additionally, the log-transformed absolute estimation was a valid predictor of the log-absolute valuation, indicating that deviations in the estimation task were partially propagated to the valuation task.

\section{Table 2}

Beta Estimates for Log-Transformed Absolute Estimation and Valuation Deviation

\begin{tabular}{lll}
\hline Factor & Estimation noise & Valuation noise \\
\hline Intercept & 0.10 & 0.05 \\
& $(0.14)$ & $(0.15)$
\end{tabular}

${ }^{2}$ The absolute deviations were non-normally distributed and needed to be log-transformed to reduce heteroscedasticity in the linear model. To allow for log transformation, we excluded values at exactly zero deviation ( $1.1 \%$ and $0.75 \%$, negligible). We considered alternative solutions but found them to be less suitable. For example, adding a constant leads to substantial heteroscedasticity in the model and a Box-Cox transformation hinders interpretability of the results.

${ }^{3}$ To test the robustness of these results, we conducted the same analysis (exploratory) on the percentage absolute deviation in estimation and valuation. This analysis yielded qualitatively the same results as the original analysis, indicating the independence of the analysis on the dependent variable (absolute deviation or percentage absolute deviation). 


\begin{tabular}{lll}
\hline Factor & Estimation noise & Valuation noise \\
\hline Complexity & $0.43^{\mathrm{a}}$ & $0.27^{\mathrm{a}}$ \\
& $(0.05)$ & $(0.06)$ \\
LogAbsEst & - & $0.14^{\mathrm{a}}$ \\
& - & $(0.03)$ \\
AbsSkewness & 0.07 & -0.04 \\
& $(0.06)$ & $(0.07)$ \\
SD & $0.03^{\mathrm{a}}$ & $0.03^{\mathrm{a}}$ \\
& $(0.002)$ & $(0.002)$ \\
EV & 0.001 & $0.004^{\mathrm{a}}$ \\
& $(0.001)$ & $(0.001)$
\end{tabular}

Note. Estimation errors are reported in parentheses. Complexity: Simple $=0$ and complex $=1$.

LogAbsEst $=$ Log-transformed absolute estimation deviation for the corresponding lottery;

AbsSkewness $=$ absolute skewness $; \mathrm{SD}=$ standard deviation $; \mathrm{EV}=$ expected value

${ }^{\text {a }}$ Indicates a beta estimate for which zero is not contained in the $95 \%$ credible interval.

\section{Discussion Experiment 1}

We found evidence against complexity aversion in valuations. Additionally, we could not find support for the potential perceptual mechanisms in estimation tasks through which complexity could affect valuations. While there was a slight underestimation bias, this bias was equally present in the evaluation of simple and complex lotteries. Similarly, while there was an increase of unsystematic deviation (noisy perception) in estimation due to complexity, and participants were aware of it according to their confidence ratings, this did not lower the valuations of complex lotteries compared to simple lotteries.

We found partial support for the response noise hypothesis, which assumes that complexity increases unsystematic noise in valuations. While the effect was inconclusive on the participant level, the valuations for the complex lotteries were more variable (31\%) than 
the valuations for the simple lotteries on the trial level. This difference was credible and suggests that complexity increases response noise.

As mentioned in the Introduction, another potential mechanism through which complexity could affect preferences is the avoidance of cognitive effort. In this case, one would expect a difference between (binary) choices and valuations because the former allows decision makers to avoid the cognitive effort of evaluating the complex option in the first place. Additionally, one would expect a weaker effect of complexity on people with high cognitive ability (e.g., university students) because they can still assess complex lotteries with reasonable accuracy, and do not need to exert as much cognitive effort than people with lower cognitive ability. To investigate this potential mechanism of cognitive effort avoidance, we conducted a second experiment in which participants completed a valuation and a choice task along with an assessment of individual cognitive ability and two behavioral process measures of cognitive effort (looking time proportion and decision speed).

\section{Experiment 2}

\section{Method}

\section{Materials}

We created six simple lotteries with two outcomes and matching complex lotteries with seven outcomes. The simple and complex lotteries had the same characteristics (expected value, standard deviation, and skewness) except for the number of outcomes. We included two levels of variance (SD: low: 5-20, and high: 35-50) and three levels of skewness (left: 2.0-1.0, none: $-0.5-0.5$, and right: 1.0-2.0). As in Experiment 1, the unit of the outcomes (e.g., 110) was not specified to keep the experiments comparable. All 12 lotteries (six simple and six complex) were presented in the valuation task. For the choice task, we added five levels of expected value differences $(-15 \%,-7.5 \%, 0 \%,+7,5 \%,+15 \%)$, resulting in 30 lottery pairs. 
To assess cognitive ability, we used the short form of the Hagen Matrices Test (Heydasch et al., 2013), a measure previously validated against a general measure of intelligence (Intelligence Structure Test: I-S-T 2000R). The test consists of six matrices that participants are asked to complete with the correct puzzle piece. In our data, the internal consistency of the measure was sufficiently high for a short version of the task $(\alpha=.65)$.

The experiment used a within-subject design, with all participants completing all the tasks and being presented the same lotteries and same matrices. The experiment consisted of three blocks. The order of the blocks was counterbalanced such that half of the participants would start with the matrices task and the other half would start with the lottery tasks. The order within the lottery tasks (choice or valuation) was randomized too.

In the valuation task, participants indicated their minimum selling price by entering a number into an input field on the screen. In the choice task, participants chose the lottery they preferred out of two options displayed on the left and right side of the screen (simple and complex). To measure participants' attention, only one option was displayed at a time. Participants could press the "F" key on the keyboard to switch between the options as often as they liked. After they had accumulated enough information to make their decision, participants could press the space bar and advance to the choice screen on which they could indicate their choice by pressing the left or right arrow key. This allowed us to measure the time spent evaluating each option. The participants were familiarized to this procedure in a practice trial. Figure 3 shows a screenshot of the valuation and choice task as an example.

\section{Figure 3}

Task Examples for Valuation (Left) and Choice (Right) 
Which lottery do you prefer?

What is your minimum selling price for this lottery?

120 with $51 \%$

43 with $49 \%$

107 with $10 \%$

111 with $20 \%$

68 with $3 \%$

119 with $22 \%$

11 with $21 \%$

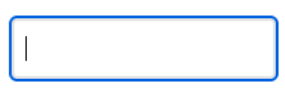

Submit
Press $\mathrm{F}$ to switch view between the lotteries.

Press Space to stop displaying the lotteries and make a choice.

Note. Participants could enter a number via the keyboard in the valuation (left) task. In this example, a simple lottery is evaluated. In the choice task (right), participants could switch between the options by pressing the " $F$ " key on the keyboard. In this example, the complex lottery is presented on the left and its corresponding simple lottery is presented on the right. After sampling at least two times, participants could press the "Space" bar to indicate their willingness to answer. On the following page, participants were then asked to indicate their choice by pressing the left or right arrow key on the keyboard. There was no time limit for the task.

The order of the lotteries within each block and the order of the outcomes within each lottery were randomized. To assess participants' understanding of the task, we employed an attention check at the beginning of each block right after the instructions, in which the participants had to indicate what they were supposed to do in the following task according to the instructions they had just read (multiple-choice question). 
Besides participants' valuations and choices, we also measured reaction times in all elements of the experiment. At the end of the experiment, we assessed demographics (age and gender) and asked participants whether they had completed the experiment in good faith. Participants were encouraged to answer this question truthfully and were additionally reminded that their answer would have no consequence for them or their probability of winning the raffle.

To analyze the data, Bayesian methods were used when available. Inferences were drawn on the basis of credible intervals, BFs, confidence intervals, and $p$ values. As for Experiment 1, all materials can be found on OSF (https://osf.io/p3sb7; https://osf.io/u5an6/) and deviations from the preregistration are reported in Appendix A.

\section{Participants and Procedure}

Based on a simulation study and pilot data $(\mathrm{N}=60)$ we determined a target sample size of $N=330$ (details in Appendix C). To account for attrition, we tested 346 participants from a stratified national U.S. sample provided by Prolific.co. The sample was representative in terms of age, sex, and ethnicity (79\% sample accuracy). Data collection lasted several days, and participants failing attention checks were consecutively excluded from the experiment, allowing for new participants to participate. The participants received a base rate payment of $£ 2.50$ and a decision-dependent bonus $(M=£ 1.02)$. Additionally, participants had the possibility to earn $£ 30$ in a raffle, with their chances of winning depending on the number of correctly solved matrices in the cognitive ability task. The valuation task incentivization was similar to that of the first experiment (BDM auction). Incentivization for the choice task was based on a single draw of one of the choices made by the participants and the lottery being played out. The values within the lotteries were converted such that participants received $0.5 \%$ of the outcome in each task. Both incentivation procedures were explained to participants based on an example task in which detailed outcomes were displayed (see also 
supplementary materials). There was no deception involved in the experiment and all information provided to the participants was truthful to the authors' best knowledge.

Data from 74 participants were excluded due to the following preregistered reasons: participant requested exclusion (eight), not understanding the instructions in one or more of the tasks (17), completing the experiment too fast (one quarter of mean time) or too slow (2.5 times mean time; five), selecting the option on the same side of the screen over $90 \%$ of the time (six), and providing low quality data (more than 10 data points had to be excluded from one person, see below) (38). As participants completed the experiment faster than expected, we slightly adjusted the exclusion criteria for the time spent on the experiment from the preregistration, in which we specified that we would set the cut-off based on the expected time (30 min). The remaining data set included 272 participants.

The experiment was built and distributed in the same way as in Experiment 1. The average age of the final sample was 41.76 years $(M d n=40$ years, $S D=15.12)$, and 131 of the participants were female, 138 were male, and three indicated a nonbinary gender identity. The experiment lasted $24.24 \mathrm{~min}$ on average $(M d n=23.03 \mathrm{~min}, S D=10.25)$.

\section{Results}

\section{Valuations}

Prior to the analysis, individual data points were removed when they were out of bounds (above the maximum or below the minimum of the outcomes presented in the lottery), which led to an exclusion of $14 \%$ of the data in the valuation task. To visualize the effect of complexity on valuations, we aggregated the data on the participant level and plotted the valuations (simple and complex) for every participant in Figure 4. The figure reveals a preference for simple lotteries: On average, participants indicated higher values for simple lotteries $\left(M_{\mathrm{s}}=91.92, S D_{\mathrm{s}}=17.29,95 \% \mathrm{CI}_{\mathrm{s}}[89.88,93.95]\right)$ than for complex lotteries $\left(M_{\mathrm{c}}=\right.$ $\left.87.76, S D_{\mathrm{c}}=23.50,95 \% \mathrm{CI}_{\mathrm{c}}[85.12,90.40]\right)$. 


\section{Figure 4}

Lottery Valuations Averaged Within Participants

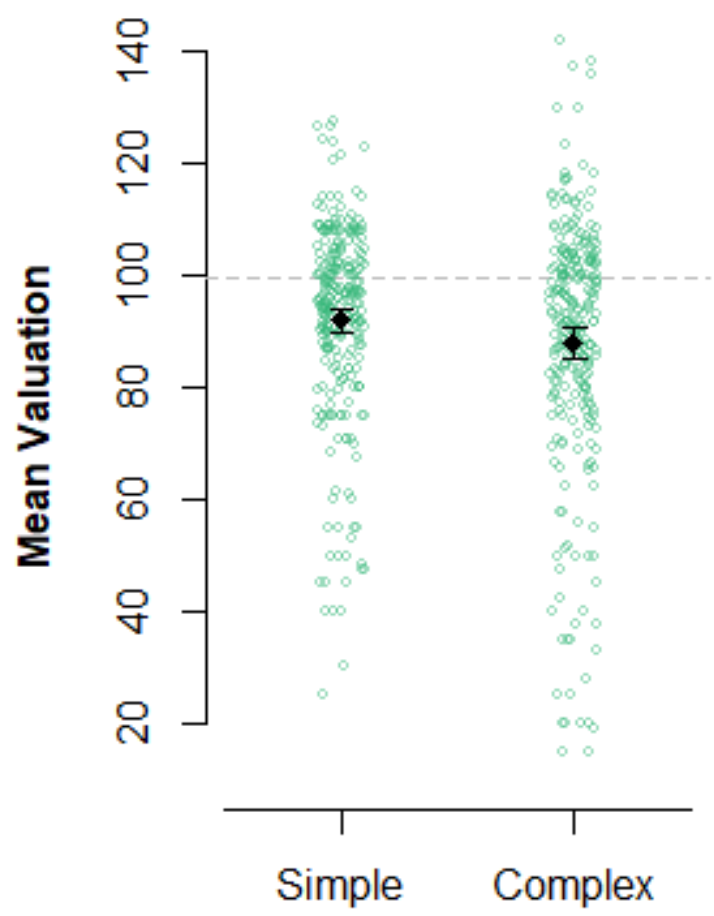

\section{Lottery}

Note. The dashed line indicates the overall mean of the experienced sequences $(M=99.62)$. Error bars denote $95 \%$ confidence intervals based on standard errors. The figure shows that simple lotteries were valued slightly higher than complex lotteries on average based on the participant aggregated data.

Employing a Bayesian multilevel regression analogous to Experiment 1, confirmed that complexity led to lower valuations for complex compared to simple gambles (see Table 3, first column). To illustrate, all else being equal, a simple lottery evaluated by a participant with median cognitive ability $(M d n=4)$ would be valued $2.7 \%$ higher than a complex lottery according to the model.

Table 3 
Beta Estimates of Valuation and Right-Side Option Choice

\begin{tabular}{|c|c|c|c|}
\hline Factor & Valuation & Choice & Choice (CE) \\
\hline \multirow[t]{2}{*}{ Intercept } & $8.30^{\mathrm{a}}$ & $1.23^{\mathrm{a}}$ & $2.34^{\mathrm{a}}$ \\
\hline & $(2.75)$ & $(0.29)$ & $(0.31)$ \\
\hline \multirow[t]{2}{*}{ Complexity } & $-7.32^{\mathrm{a}}$ & $-2.39^{a}$ & $-4.85^{a}$ \\
\hline & $(1.53)$ & $(0.53)$ & $(0.55)$ \\
\hline \multirow[t]{2}{*}{$\operatorname{Cog} \mathrm{A}$} & -0.44 & -0.11 & -0.07 \\
\hline & $(0.33)$ & $(0.08)$ & $(0.08)$ \\
\hline \multirow[t]{2}{*}{ EV } & $0.94^{\mathrm{a}}$ & - & - \\
\hline & $(0.02)$ & - & - \\
\hline \multirow[t]{2}{*}{$\mathrm{dEV}$} & - & 1.64 & 1.79 \\
\hline & - & $(1.31)$ & $(1.38)$ \\
\hline \multirow[t]{2}{*}{ Skewness } & $1.90^{\mathrm{a}}$ & - & - \\
\hline & $(0.32)$ & - & - \\
\hline \multirow[t]{2}{*}{ SD } & $-0.22^{\mathrm{a}}$ & - & - \\
\hline & $(0.04)$ & - & - \\
\hline \multirow[t]{2}{*}{ Complexity $\times$ CogA } & $1.17^{\mathrm{a}}$ & 0.22 & 0.13 \\
\hline & $(0.40)$ & $(0.14)$ & $(0.14)$ \\
\hline \multirow[t]{2}{*}{$\mathrm{dEV} \times \operatorname{Cog} \mathrm{A}$} & - & $2.10^{\mathrm{a}}$ & $2.18^{\mathrm{a}}$ \\
\hline & - & $(0.36)$ & $(0.37)$ \\
\hline \multirow[t]{2}{*}{ LTP } & - & - & $-0.65^{\mathrm{a}}$ \\
\hline & - & - & $(0.05)$ \\
\hline \multirow[t]{2}{*}{ Speed } & - & - & -0.01 \\
\hline & - & - & $(0.01)$ \\
\hline \multirow[t]{2}{*}{ Complexity $\times$ LTP } & - & - & $1.47^{\mathrm{a}}$ \\
\hline & - & - & $(0.07)$ \\
\hline \multirow[t]{2}{*}{ Complexity $\times$ Speed } & - & - & 0.02 \\
\hline & - & - & $(0.01)$ \\
\hline
\end{tabular}

Note. Estimation errors are reported in parentheses. Choice $(\mathrm{CE})=$ Choice model including process measures of cognitive effort; Complexity: Simple $=0$ and complex $=1$ in valuations, simple option right-side $=0$ and complex option right-side $=1$ in choices. $\operatorname{Cog} \mathrm{A}=\operatorname{cog}$ nitive 
ability; $\mathrm{EV}=$ expected value; $\mathrm{dEV}=$ expected value difference right - left $; \mathrm{SD}=$ standard deviation; LTP = looking time proportion complex/simple; speed $=$ number of decisions per minute.

${ }^{\text {a }}$ Indicates a beta estimate for which zero is not contained in the $95 \%$ credible interval.

Additionally, there was an interaction between complexity and cognitive ability, indicating that people with higher cognitive ability showed less undervaluation of the complex compared to the simple lottery. As can be seen in Figure 5, the disparity between valuations of simple and complex lotteries decreased with higher cognitive ability and became undetectable at a cognitive ability level of 4 (out of 6).

\section{Figure 5}

Difference in Valuation Between Simple and Complex Lotteries for Participants with Different Levels of Cognitive Ability based on Descriptives (Aggregated)



Note. The data show that the difference decreases as cognitive ability increases. The difference disappears at a cognitive ability level of 4 . Error bars denote $95 \%$ confidence intervals based on standard errors. $\mathrm{C}=$ Complex; $\mathrm{S}=$ simple. 
Finally, the multilevel model revealed that right skewness, low variance, and higher expected value led to higher valuations. These effects closely resembled those in Experiment 1 , thus replicating them. Since there was a systematic effect in valuation, we could not conduct an analysis of absolute deviation in valuation as in Experiment 1 (as originally planned) because such an analysis would be confounded by the systematic effect.

\section{Choice}

Prior to the analysis, individual data points were removed when the participants took longer than 1 minute or less than 1 second to look at a lottery in the choice task ( $3 \%$ of data), indicating insufficient attention to the task. To visualize the effect of complexity on choice, we aggregated the data on the participant level and plotted the frequencies of complex choice proportions per individual in Figure 6. As can be seen in the figure, some individuals were clearly complexity averse, as they never chose the complex option. The opposite (people always choosing the complex option) was observed in only one of 272 participants.

\section{Figure 6}

Individual Choice Proportions of the Complex Option (Panel A) and of the Complex Option Split by Expected Value (EV) Difference (Panel B) 
A

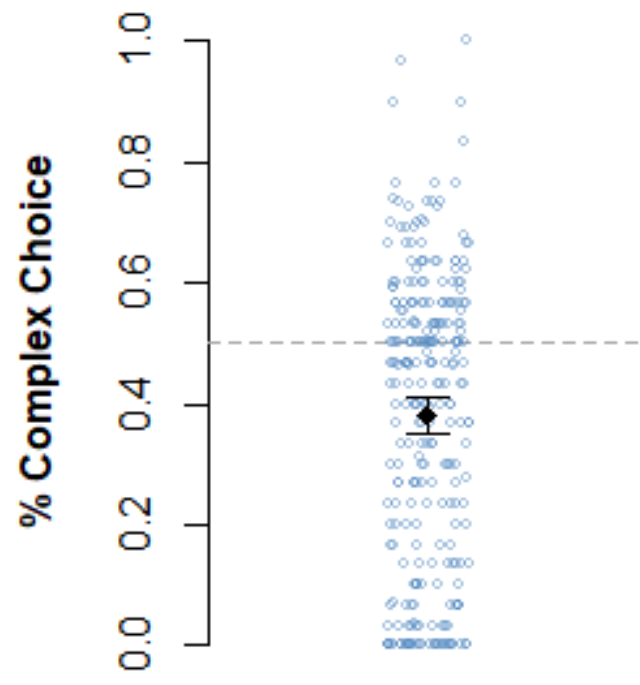

Overall
B



EV Difference (C-S)

Note. The dashed lines indicate an unbiased choice proportion of 50\%. Dots below the dashed lines indicate complexity aversion. Error bars denote $95 \%$ confidence intervals based on standard errors. $\mathrm{C}=$ Complex; $\mathrm{S}=$ simple. The data is aggregated within participants.

\section{Figure 7}

Interaction Plots for Cognitive Ability and Complexity in Choices 

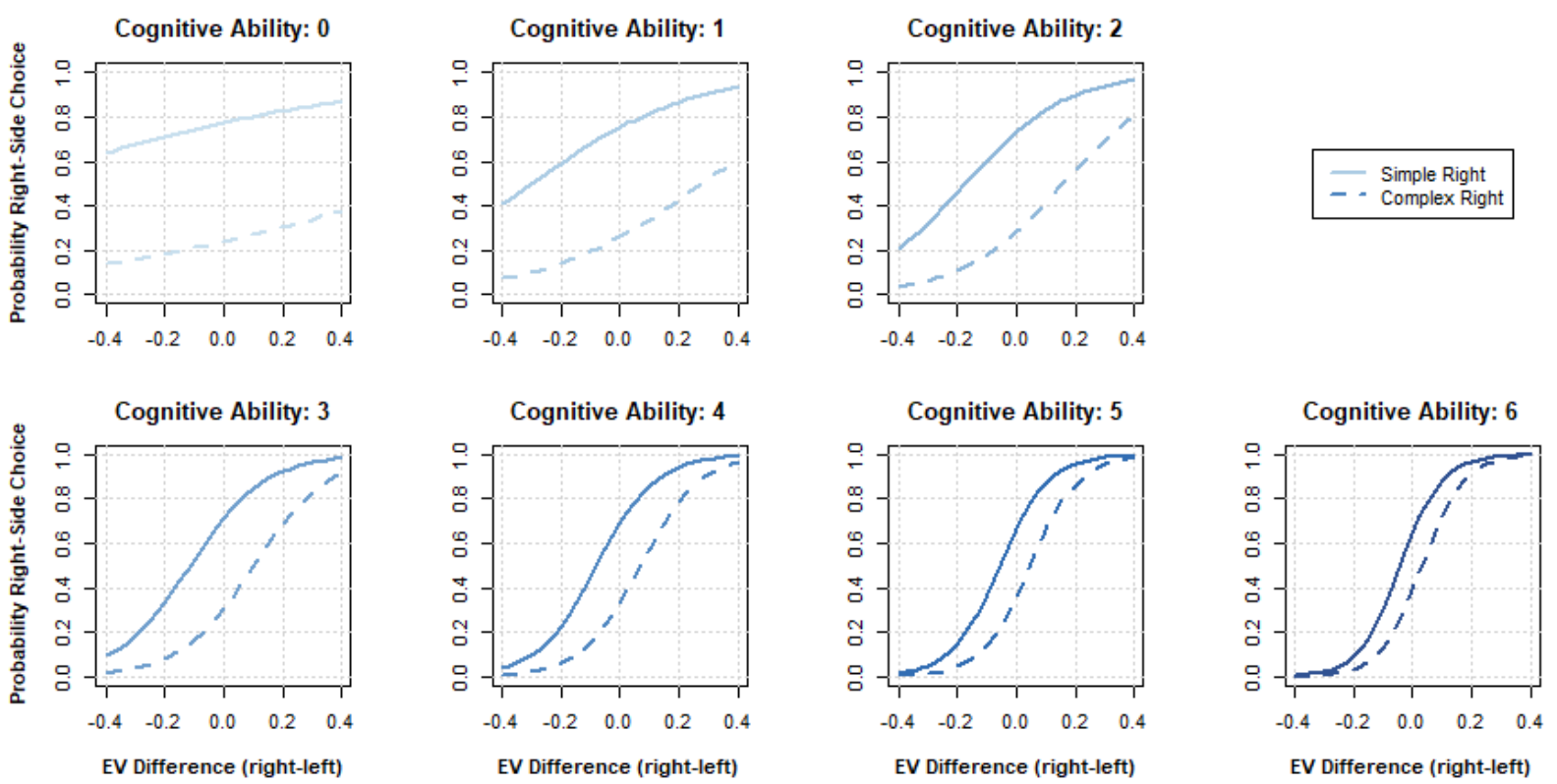

Note. Higher cognitive ability leads to higher expected value (EV) sensitivity (steeper decision curve). EV differences in the experiment had a range of $\pm 15 \%$. The $x$ axis of the plots was extended to $\pm 40 \%$ to increase clarity and visibility.

A multilevel Bayesian regression with choice as dependent variable (right-side option $=1$, left-side option $=0$; to test the influence of complexity outside of the intercept), participant random intercepts and random slopes for each factor, and default priors confirmed that complex gambles were chosen less often than simple gambles (see Table 3, second column). To illustrate, all else being equal, complexity aversion in an exemplary participant with median cognitive ability $(M d n=4)$ was offset if a complex option had a $7.4 \%$ higher expected value than the simple lottery according to the model. Furthermore, the analysis showed that there was an interaction effect of cognitive ability and expected value, indicating that participants with higher cognitive ability were more sensitive to expected value differences between the options. This interaction is visualized in Figure 7. However, there was no credible interaction effect of cognitive ability and complexity, indicating that participants with higher cognitive ability were not less complexity averse beyond being more 
sensitive to expected value differences. Finally, the intercept of the model was credibly positive, indicating that participants chose the right-side option more often regardless of content. Because we counterbalanced the position of the options on the screen, this preference for options on the right did not bias any of the results reported above.

\section{Cognitive Effort}

To test the influence of cognitive effort on the dislike of complexity, we included two additional interactions in the model: looking time proportion (LTP), defined as LTP $=$ $\frac{\text { looking time complex }}{\text { looking time simple }}$ and decision speed, defined as $\frac{60}{\text { decision time }}=$ choices per minute. The extended model revealed an interaction between LTP and complexity, indicating that the complex gamble was chosen more often when participants paid more attention to it (see Table 3, third column, and Figure 8 for a plot of the descriptives). Interestingly, at an LTP around 3.5, which would equal the proportion of information presented (two vs. seven outcomes), the bias disappears or even inverts, as people eventually preferred the complex option. In contrast, there was no credible interaction between complexity and decision speed, indicating that complex gambles were not chosen less often during fast decisions.

\section{Figure 8}

Descriptive Plot of Looking Time Proportion and the Complex Choice Proportion 


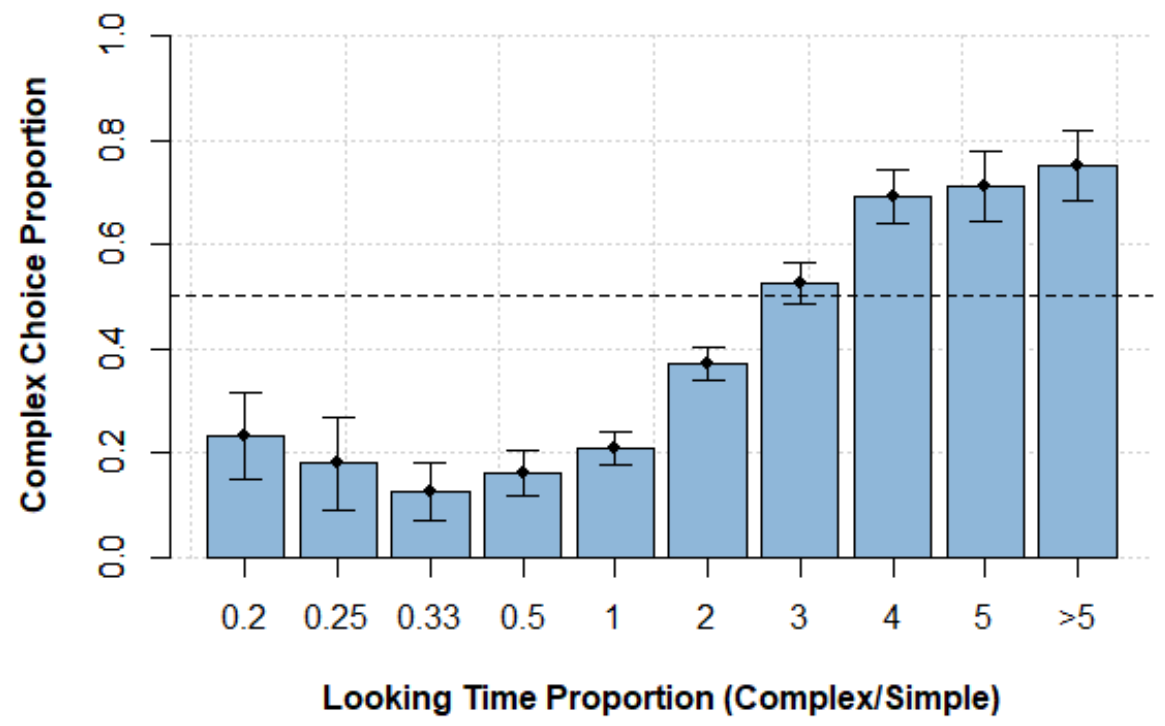

Note. Looking time proportion (LTP) was binned in nine symmetrical bins denoted by their upper limit and one summary bin (> 5) and then aggregated within and eventually over all participants. Higher LTP for the complex option led to less or even an inversion of the complexity bias according to the interaction effect. Error bars denote $95 \%$ confidence intervals based on standard errors.

\section{Age Effects}

Recent literature on complexity aversion illuminated its relationship with age (Zilker et al., 2020; Zilker \& Pachur, 2020). This led us to conduct an additional exploratory analysis on valuation and choice that included age as a factor instead of cognitive ability. In choices, age (standardized) was a credible moderator of complexity aversion, interacting with complexity $(\beta=-0.06,95 \%$ CI $[-0.09,-0.03])$ and expected value sensitivity $(\beta=-0.13,95 \%$ CI $[-0.21,-0.05])$. To illustrate, the model that included age as a predictor had a good, but not significantly better fit (LOOIC (leave-one-out cross-validation (LOO) information criterion) = -3723, $S E=47.8$ ), than the model including cognitive ability (LOOIC $=-3717, S E=47.8$, $\left.\Delta \mathrm{LOOIC}_{\text {ca-age }}=-5.5, S E=3.8,95 \% \mathrm{CI}[-13.0,1.9]\right)$, indicating that age was an equally good predictor as the employed measure of cognitive ability. In contrast, in valuations, age 
(standardized) was not a credible moderator of complexity aversion $(\beta=-0.04,95 \%$ CI [-0.12, 0.04]). In summary, age seems to be a valid predictor in choices, but not in valuations.

\section{Discussion Experiment 2}

In a stratified national sample (79\% accuracy), we found evidence of complexity aversion in valuations and choice. In the valuation task, complex options were valued $2.7 \%$ less than simple lotteries on average. In contrast, in the choice task, a complex option needed an expected value $7.4 \%$ higher than the simple option to be equally attractive on average (see Figure 6). This suggests that the effect of complexity was stronger in choices than in valuations, a valuation-choice gap. Furthermore, participants with higher cognitive ability showed less complexity aversion in valuations and more expected value sensitivity in choices. While this supports the general moderating role of individual cognitive ability, it does not support our hypothesis that cognitive ability decreases complexity aversion in choices beyond increasing expected value sensitivity. Lastly, the LTP measure of cognitive effort was a strong and credible predictor of complexity averse choice. Taken together, the observed valuationchoice gap, the partially moderating influence of cognitive ability, and the predictive quality of one of the process measures for cognitive effort are most in line with the hypothesis that complex options are chosen less often because the necessary cognitive effort to evaluate them is disliked and avoided.

\section{Overall Discussion}

Based on two experiments (one with a stratified national sample) we found that complexity affects risk taking in both, choices between two lotteries and valuations of single lotteries. Importantly, the effect of complexity was stronger in the choice than in the valuation task. In the choice task, complexity affected choice proportions only in trials where participants presumably avoided to process the complex lottery. As focusing on the easier lottery was not possible in the single valuation task, we propose the avoidance of cognitive effort as a cognitive mechanism to explain the difference between choices and valuations. 
Finally, to explain why the evidence for complexity aversion in valuations were ambiguous, we examined individual differences in cognitive ability. In Experiment 2, we found that only participants with lower cognitive ability discounted the complex options compared to easy ones. As Experiment 1 consisted of a student sample, we assume that cognitive ability was high in this participant pool, that way showing no effect of complexity on valuations.

\section{The Cognitive Processes of Complexity Aversion}

Furthermore, cognitive ability also affected choices. However, the moderating effect in choices was restricted to increasing expected value sensitivity. This indicates that the effect might not be as straightforward as expected. Future research could shed light on the details of this effect.

We also examined decision speed as a process measure and found that it was not a valid predictor of complexity aversion. This could indicate that complexity aversion should not be interpreted as general carelessness or sloppiness on the part of the study participants. This is in line with related findings showing that time pressure did not systematically affect the propensity to choose simpler options (Olschewski \& Rieskamp, 2021).

We also found support for the hypothesis that complexity aversion is partly driven by response noise. More specifically, we found an increase in preference variability for complex options in the first experiment in which complexity led to substantially noisier valuations (31\%). This increase could have amplified the effect of complexity aversion reported in previous studies in which the higher expected value was predominantly assigned to the complex option and a choice of the option with lower expected value was interpreted as a potential dislike of complexity (Huck \& Weizsäcker, 1999; Sonsino et al., 2002; see also Olschewski et al., 2018). Apart from that, we found no evidence in support of the hypothesis that complexity aversion results from a (perceptual) underestimation, as there was no difference in the mean estimation between complex and simple lotteries in Experiment 1. Similarly, we did not find evidence in support of a dislike of noisy perception: Participants 
indeed perceived their estimates to be less precise when evaluating complex lotteries in Experiment 1, as indicated by their confidence valuations, but this did not translate to a dislike (i.e., lower valuations) for complex gambles. To the extent that decision makers are risk averse, this can be interpreted as maladaptive, because decision-maker error constitutes an additional source of uncertainty and hence risk. As a limitation, it has to be considered that these two hypotheses could be tested only in Experiment 1 that was based on a sample of university students. It is possible that perceptual influences might be more relevant in a more heterogeneous sample.

Finally, because we controlled for skewness and variance in our lottery stimuli, we could assess the influence of these factors on valuations and estimations. Participants' risktaking behavior was generally in line with previous findings in the literature. Participants were overall risk averse (e.g., Holt \& Laury, 2002) and they preferred options with a high rare outcome (i.e., right-skewed options) over options with a low rare outcome (i.e., left-skewed options; Spiliopoulos \& Hertwig, 2019; Tversky \& Kahneman, 1992). Unlike in studies in decisions from experience (Olschewski et al., 2021), the effect of variance on estimation was not credible. Hence, avoiding high-variance lotteries in decisions from description cannot be explained by an estimation bias.

\section{Implications}

Response noise in valuations and estimations was substantially higher for complex lotteries compared to their simpler counterparts. As this noise effect was already present on the estimation level, this implies that it was most likely caused by errors during information integration because more information has to be integrated for complex lotteries. An increase of unsystematic noise is something that future experiment designs should account for. To avoid inferring bias when there is only noise, experimental designs with symmetrical stimuli variation should be employed. Likewise, deviations from a decision proportion of $100 \%$ 
should be interpreted cautiously because a decision process with maximum noise will lead to a choice proportion of 50:50.

Biased preferences for complex lotteries were especially prevalent in choices, but less robust in valuations. We explained the general finding and the difference between the elicitation formats with a dislike of cognitive effort. This implies that future experimental designs should take complexity into account because eliciting risk preferences from stimuli that differ in complexity can lead to unintentionally biased data. Moreover, the moderating influence of cognitive ability suggests that individual differences play an important role in how people cope with complexity. This is in line with previous research on individual differences (Moffat et al., 2015) and age effects (Zilker et al., 2020) in complexity aversion. Finally, the observed quantitative valuation-choice gap in the dislike of complexity suggests that the bias can be reduced by presenting alternatives one at a time (valuation). Presumably, this is because this format requires participants to engage with every option. In other words, valuations were less biased by complexity than choices and might be the preferable paradigm to measure risk preferences if differing complexity between target options cannot be avoided.

\section{Limitations and Future Research}

One could have expected an effect of cognitive ability on complexity aversion also in choice, assuming that cognitive ability reduces cognitive effort in choices the same way as in valuations. While we did not find a direct significant interaction, we found a moderating influence of cognitive ability on expected value sensitivity. In our experimental design, a decision maker who is more sensitive to expected value will be less affected by an unsystematic effect of complexity. This interaction provides indirect evidence for reduced complexity aversion (stemming from an unsystematic effect in asymmetrical experimental designs) in choices for people with high cognitive abilities. Moreover, it is possible that the there is an interaction between cognitive ability and cognitive effort, meaning that cognitive 
ability might have lost its predictive validity because cognitive effort was the stronger predictor in the model. However, more research is necessary to confirm these relations.

Further, we interpreted the time spent evaluating each option (LTP) as a measure of attention and reported a disappearance or inversion of the bias at sufficient attention in the choice task. However, the causal direction could also be reversed. Assuming the bias is a plain preference (not dependent on the avoidance of cognitive effort), the LTP could be an expression of preference, as it has been shown that people look longer at options they prefer (e.g., Shimojo et al., 2003). We find both directions plausible; the effect is likely bidirectional (Krajbich et al., 2010). Interestingly, a recent study (Zilker \& Pachur, 2020) did not find that option complexity contributes to age effects in framing, loss aversion, or delay discounting. These findings conflict with our assumption of a relatively general mechanism (avoidance of cognitive effort) as the most probable explanation of complexity aversion. Further research is needed to reconcile the two findings.

In addition, future research should investigate how dislike of cognitive effort shapes behavior beyond controlled lab experiments, for example, in investment decisions, consumer choice, and potentially also more general learning contexts in which cognitive effort plays a central role. To the degree that individual differences in dislike of cognitive effort are partially learned through the association of invested effort and received reward (e.g., Inzlicht et al., 2018), complexity preferences might be malleable. Moreover, this would suggest that complexity aversion can be unlearned. Future experiments could explore this possibility, as it could inform intervention designs intended to reduce complexity aversion.

\section{Conclusion}

In daily live, people face an ever-increasing complexity in many domains such as financial and consumer decisions. We showed that differences in complexity systematically impact risk taking and that individuals with low cognitive abilities dislike complex options in particular. On a societal level, this mechanism has the potential to increase income and wealth 
inequality, as people with low cognitive abilities might shy away from complex, but highly rewarding options such as investing in stocks. We also showed that the impact of complexity on risk taking can be mitigated when presenting options sequentially, rather than simultaneously. Thus, it is important for researchers to understand and model the effect of complexity on preferential decisions and for choice architects to take option complexity into account when designing choice environments to guarantee a level playing field for all individuals.

\section{CRediT statement}

Yvonne Oberholzer: Conceptualization, Data Curation, Formal Analysis, Investigation, Methodology, Project Administration, Resources, Software, Validation, Visualization, Writing - Original Draft, Writing - Review \& Editing. Sebastian Olschewski: Conceptualization, Funding Acquisition, Methodology, Supervision, Writing - Review \& Editing. Benjamin Scheibehenne: Conceptualization, Funding Acquisition, Methodology, Supervision, Writing - Review \& Editing.

\section{Acknowledgments}

This research has been funded by the Swiss National Science Foundation (SNSF) Grant Nr. 100014_175849. We thank Anita Todd for editing the manuscript.

\section{Supplementary Materials}

The experiment, an excerpt of the instructions, the data and the analyses are available on the OSF project page (https://osf.io/u5an6/). 


\section{References}

Andersson, O., Holm, H. J., Tyran, J.-R., \& Wengström, E. (2016). Risk aversion relates to cognitive ability: Preferences or noise? Journal of the European Economic Association, 14(5), 1129-1154. https://doi.org/10.1111/jeea.12179

Becker, G. M., Degroot, M. H., \& Marschak, J. (1964). Measuring utility by a single-response sequential method. Behavioral Science, 9(3), 226-232. https://doi.org/10.1002/bs.3830090304

Blaufus, K., \& Ortlieb, R. (2009). Is simple better? A conjoint analysis of the effects of tax complexity on employee preferences concerning company pension plans. Schmalenbach Business Review, 61(1), 60-83. https://doi.org/10.1007/BF03396780

Bopp, K. L., \& Verhaeghen, P. (2005). Aging and verbal memory span: A meta-analysis. The Journals of Gerontology: Series B, 60(5), P223-P233. https://doi.org/10.1093/geronb/60.5.P223

Boxall, P., Adamowicz, W. L. (Vic), \& Moon, A. (2009). Complexity in choice experiments: Choice of the status quo alternative and implications for welfare measurement. Australian Journal of Agricultural and Resource Economics, 53(4), 503-519. https://doi.org/10.1111/j.1467-8489.2009.00469.x

Bruce, A. C., \& Johnson, J. E. V. (1996). Decision-making under risk: Effect of complexity on performance. Psychological Reports, 79(1), 67-76. https://doi.org/10.2466/pr0.1996.79.1.67

Bürkner, P.-C. (2018). Advanced Bayesian multilevel modeling with the R package brms. The R Journal, 10(1), 395-411.

Burks, S. V., Carpenter, J. P., Goette, L., \& Rustichini, A. (2009). Cognitive skills affect economic preferences, strategic behavior, and job attachment. Proceedings of the National Academy of Sciences, 106(19), 7745-7750. https://doi.org/10.1073/pnas.0812360106 
Champely, S. (2020). pwr: Basic functions for power analysis. $R$ package version 1.3-0

[Computer software manual]. https://CRAN.R-project.org/package=pwr

Dehaene, S. (1992). Varieties of numerical abilities. Cognition, 44(1), 1-42. https://doi.org/10.1016/0010-0277(92)90049-N

Dehaene, S. (2011). The Number Sense: How the Mind Creates Mathematics, Revised and Updated Edition. Oxford University Press, USA.

Dhar, R. (1997a). Consumer preference for a no-choice option. Journal of Consumer Research, 24(2), 215-231. https://doi.org/10.1086/209506

Dhar, R. (1997b). Context and task effects on choice deferral. Marketing Letters, 8(1), 119130. https://doi.org/10.1023/A:1007997613607

Evangelidis, I., Lev, J., \& Simonson, I. (2022). A Reexamination of the Impact of Decision Conflict on Choice Deferral. Management Science, Forthcoming

Fox, C. R., \& Ülkümen, G. (2011). Distinguishing two dimensions of uncertainty. In W. Brun, G. Keren, G. Kirkeboen, \& H. Montgomery (Eds.), Perspectives on thinking, judging, and decision making (pp. 21-35). Oslo, Norway: Universitetsforlaget.

Frank, R. G., \& Lamiraud, K. (2009). Choice, price competition and complexity in markets for health insurance. Journal of Economic Behavior \& Organization, 71(2), 550-562. https://doi.org/10.1016/j.jebo.2009.04.005

Grady, C. (2012). The cognitive neuroscience of ageing. Nature Reviews Neuroscience, 13(7), 491-505. https://doi.org/10.1038/nrn3256

Greifeneder, R., Scheibehenne, B., \& Kleber, N. (2010). Less may be more when choosing is difficult: Choice complexity and too much choice. Acta Psychologica, 133(1), 45-50. https://doi.org/10.1016/j.actpsy.2009.08.005

Henninger, F., Shevchenko, Y., Mertens, U. K., Kieslich, P. J., \& Hilbig, B. E. (2019). lab.js: A free, open, online study builder. PsyArXiv. https://doi.org/10.31234/osf.io/fqr49 
Heydasch, T., Haubrich, J., \& Renner, K.-H. (2013). The short version of the Hagen Matrices Test (HMT-S): A 6-item induction intelligence test. methods, data, analyses, 7(2). https://doi.org/10.12758/MDA.2013.011

Holt, C. A., \& Laury, S. K. (2002). Risk aversion and incentive effects. American Economic Review, 92(5), 1644-1655. https://doi.org/10.1257/000282802762024700

Horn, J. L., \& Cattell, R. B. (1967). Age differences in fluid and crystallized intelligence. Acta Psychologica, 26, 107-129. https://doi.org/10.1016/0001-6918(67)90011-X

Huck, S., \& Weizsäcker, G. (1999). Risk, complexity, and deviations from expected-value maximization: Results of a lottery choice experiment. Journal of Economic Psychology, 20(6), 699-715. https://doi.org/10.1016/S0167-4870(99)00031-8

Inzlicht, M., Shenhav, A., \& Olivola, C. Y. (2018). The effort paradox: Effort is both costly and valued. Trends in Cognitive Sciences, 22(4), 337-349. https://doi.org/10.1016/j.tics.2018.01.007

Izard, V., \& Dehaene, S. (2008). Calibrating the mental number line. Cognition, 106(3), 1221-1247. https://doi.org/10.1016/j.cognition.2007.06.004

Krajbich, I., Armel, C., \& Rangel, A. (2010). Visual fixations and the computation and comparison of value in simple choice. Nature Neuroscience, 13(10), 1292-1298. https://doi.org/10.1038/nn.2635

Kool, W., McGuire, J. T., Rosen, Z. B., \& Botvinick, M. M. (2010). Decision making and the avoidance of cognitive demand. Journal of Experimental Psychology. General, 139(4), 665-682. https://doi.org/10.1037/a0020198

Lange, K., Kühn, S., \& Filevich, E. (2015). “Just Another Tool for Online Studies” (JATOS): An easy solution for setup and management of web servers supporting online studies. PLoS ONE, 10(6), Article e0130834. https://doi.org/10.1371/journal.pone.0130834 
Mador, G., Sonsino, D., \& Benzion, U. (2000). On complexity and lotteries' evaluationThree experimental observations. Journal of Economic Psychology, 21(6), 625-637. https://doi.org/10.1016/S0167-4870(00)00023-4

https://doi.org/10.1086/208882Moffatt, P. G., Sitzia, S., \& Zizzo, D. J. (2015). Heterogeneity in preferences towards complexity. Journal of Risk and Uncertainty, 51(2), 147-170. https://doi.org/10.1007/s11166-015-9226-3

Oberholzer, Y., Olschewski, S., \& Scheibehenne, B. (2021). Complexity Aversion in Risky Choices and Valuations: Moderators and Possible Causes. PsyArXiv. https://doi.org/10.31234/osf.io/tnvzr

Oberholzer, Y., Olschewski, S., \& Scheibehenne, B. (2021, August 12). Complexity Aversion in Risk Preferences. Retrieved from osf.io/u5an6

Olschewski, S., Newell, B. R., Oberholzer, Y., \& Scheibehenne, B. (2021). Valuation and estimation from experience. Journal of Behavioral Decision Making. Advance online publication. https://doi.org/10.1002/bdm.2241

Olschewski, S., \& Rieskamp, J. (2021). Distinguishing three effects of time pressure on risk taking: Choice consistency, risk preference, and strategy selection. Journal of Behavioral Decision Making. Advance online publication. https://doi.org/10.1002/bdm.2228

Olschewski, S., Rieskamp, J., \& Scheibehenne, B. (2018). Taxing cognitive capacities reduces choice consistency rather than preference: A model-based test. Journal of Experimental Psychology: General, 147(4), 462-484. https://doi.org/10.1037/xge0000403

R Core Team. (2020). R: A language and environment for statistical computing. [Computer software manual]. R Foundation for Statistical Computing. https://www.Rproject.org/. 
Sandra, D. A., \& Otto, A. R. (2018). Cognitive capacity limitations and need for cognition differentially predict reward-induced cognitive effort expenditure. Cognition, 172, 101-106. https://doi.org/10.1016/j.cognition.2017.12.004

Scheibehenne, B. (2019). The psychophysics of number integration: Evidence from the lab and from the field. Decision, 6(1), 61-76. https://doi.org/10.1037/dec0000089

Schley, D. R., \& Peters, E. (2014). Assessing “economic value”: Symbolic-number mappings predict risky and riskless valuations. Psychological Science, 25(3), 753-761. https://doi.org/10.1177/0956797613515485

Schneider-Garces, N. J., Gordon, B. A., Brumback-Peltz, C. R., Shin, E., Lee, Y., Sutton, B. P., Maclin, E. L., Gratton, G., \& Fabiani, M. (2010). Span, CRUNCH, and beyond: Working memory capacity and the aging brain. Journal of Cognitive Neuroscience, 22(4), 655-669. https://doi.org/10.1162/jocn.2009.21230

Shimojo, S., Simion, C., Shimojo, E., \& Scheier, C. (2003). Gaze bias both reflects and influences preference. Nature Neuroscience, 6(12), 1317-1322. https://doi.org/10.1038/nn1150

Siegler, R. S., \& Opfer, J. E. (2003). The development of numerical estimation: Evidence for multiple representations of numerical quantity. Psychological Science, 14(3), 237243. https://doi.org/10.1111/1467-9280.02438

Slovic, P., \& Lichtenstein, S. (1983). Preference reversals: A broader perspective. The American Economic Review, 73(4), 596-605.

Sonsino, D., Benzion, U., \& Mador, G. (2002). The complexity effects on choice with uncertainty-Experimental evidence. The Economic Journal, 112(482), 936-965. https://doi.org/10.1111/1468-0297.00073

Spiliopoulos, L., \& Hertwig, R. (2019). Nonlinear decision weights or moment-based preferences? A model competition involving described and experienced skewness. Cognition, 183, 99-123. https://doi.org/10.1016/j.cognition.2018.10.023 
Stanovich, K. E. (2018). Miserliness in human cognition: The interaction of detection, override and mindware. Thinking \& Reasoning, 24(4), 423-444. https://doi.org/10.1080/13546783.2018.1459314

Tversky, A., \& Kahneman, D. (1992). Advances in prospect theory: Cumulative representation of uncertainty. Journal of Risk and Uncertainty, 5(4), 297-323. https://doi.org/10.1007/BF00122574

Tversky, A., \& Shafir, E. (1992). Choice under conflict: The dynamics of deferred decision. Psychological Science, 3(6), 358-361. https://doi.org/10.1111/j.14679280.1992.tb00047.x

Tversky, A., Slovic, P., \& Kahneman, D. (1990). The causes of preference reversal. The American Economic Review, 80(1), 204-217.

Westbrook, A., Kester, D., \& Braver, T. S. (2013). What is the subjective cost of cognitive effort? Load, trait, and aging effects revealed by economic preference. PLOS ONE, 8(7), Article e68210. https://doi.org/10.1371/journal.pone.0068210

Zilker, V., Hertwig, R., \& Pachur, T. (2020). Age differences in risk attitude are shaped by option complexity. Journal of Experimental Psychology: General, 149(9), 1644-1683. https://doi.org/10.1037/xge0000741

Zilker, V., \& Pachur, T. (2020). Does option complexity contribute to the framing effect, loss aversion, and delay discounting in younger and older adults? Journal of Behavioral Decision Making. Advance online publication. https://doi.org/10.1002/bdm.2224 


\section{Appendix A}

The preregistration for both experiments can be found on OSF (https://osf.io/jpsur; https://osf.io/p3sb7). In Experiment 1, we deviated from the preregistration as follows. There was no deviation in the experiment design. Deviations in exclusion criteria include the following: As reported on page 12, we alleviated the exclusion criterion on the basis of the instruction checks because we judged it to be misunderstood by the participants. Additionally, we adjusted the exclusion criterion on the basis of experiment completion time by setting the boundaries (one quarter of the time and twice the time) on the basis of the actual mean completion time and not the expected completion time (because the actual mean completion time was slightly longer). Finally, we did not apply the exclusion criterion intended to detect calculator use in participants because we conducted the experiment in a controlled laboratory environment. Deviations in the analysis are detailed in Table A1.

\section{Table A1}

Deviations in Analysis, Experiment 1

\begin{tabular}{lllll}
\hline Analysis & Text & Change & Reasoning & Consequence \\
& page no. & & \\
\hline $\begin{array}{l}\text { Complexity } \\
\text { aversion in }\end{array}$ & p. 13 & $\begin{array}{l}\text { Analysis on } \\
\text { individual } \\
\text { valuations } \\
\text { (confirmatory) }\end{array}$ & $\begin{array}{l}\text { Accounting for the } \\
\text { repeated measures }\end{array}$ & $\begin{array}{l}\text { No qualitative } \\
\text { difference }\end{array}$ \\
$\begin{array}{l}\text { Complexity } \\
\text { aversion in }\end{array}$ & p. 14 & Analysis on & Accounting for the & No qualitative \\
estimations & & individual & repeated measures & difference \\
(confirmatory) & & aggregated data & structure of the data & \\
\hline
\end{tabular}




\begin{tabular}{|c|c|c|c|c|}
\hline Analysis & $\begin{array}{l}\text { Text } \\
\text { page no. }\end{array}$ & Change & Reasoning & Consequence \\
\hline $\begin{array}{l}\text { Multilevel } \\
\text { model for } \\
\text { valuations } \\
\text { (confirmatory) }\end{array}$ & p. 15 & $\begin{array}{l}\text { Excluded } \\
\text { predictor } \\
\text { estimation (i.e., } \\
\text { separate analysis } \\
\text { for estimation) }\end{array}$ & $\begin{array}{l}\text { Accounting for high } \\
\text { collinearity between } \\
\text { the factors gamble } \\
\text { expected value and } \\
\text { estimation } r(2,384)= \\
.91, p<.001 \text {. }\end{array}$ & $\begin{array}{l}\text { No qualitative } \\
\text { difference }\end{array}$ \\
\hline $\begin{array}{l}\text { Confidence } \\
\text { ratings in } \\
\text { estimations } \\
\text { (confirmatory) }\end{array}$ & p. 16 & $\begin{array}{l}\text { Analysis on } \\
\text { individual } \\
\text { aggregated data }\end{array}$ & $\begin{array}{l}\text { Accounting for the } \\
\text { repeated measures } \\
\text { structure of the data }\end{array}$ & $\begin{array}{l}\text { No qualitative } \\
\text { difference }\end{array}$ \\
\hline $\begin{array}{l}\text { Unsystematic } \\
\text { deviation in } \\
\text { valuations and } \\
\text { estimations } \\
\text { (confirmatory) }\end{array}$ & p. 16 & $\begin{array}{l}\text { Analysis on } \\
\text { individual } \\
\text { aggregated data }\end{array}$ & $\begin{array}{l}\text { Accounting for the } \\
\text { repeated measures } \\
\text { structure of the data }\end{array}$ & $\begin{array}{l}\text { No qualitative } \\
\text { difference }\end{array}$ \\
\hline $\begin{array}{l}\text { Influences on } \\
\text { unsystematic } \\
\text { deviation in } \\
\text { estimations and } \\
\text { valuations } \\
\text { (exploratory) }\end{array}$ & p. 17 & $\begin{array}{l}\text { Log } \\
\text { transformation } \\
\text { and exclusion of } \\
\text { values at exactly } \\
\text { zero }\end{array}$ & $\begin{array}{l}\text { Absolute deviations } \\
\text { are not normally } \\
\text { distributed. Zeros } \\
\text { cannot be handled in } \\
\text { log transformations. } \\
\text { Alternative solutions } \\
\text { were considered but } \\
\text { rejected; e.g., adding } \\
\text { a constant leads to } \\
\text { substantial } \\
\text { heteroscedasticity in } \\
\text { the model and a } \\
\text { Box-Cox } \\
\text { transformation } \\
\text { hinders }\end{array}$ & $\begin{array}{l}\text { Original model } \\
\text { not comparable } \\
\text { because of large } \\
\text { heteroscedasticity }\end{array}$ \\
\hline
\end{tabular}




\begin{tabular}{|c|c|c|c|c|}
\hline Analysis & $\begin{array}{l}\text { Text } \\
\text { page no. }\end{array}$ & Change & Reasoning & Consequence \\
\hline & & & $\begin{array}{l}\text { interpretability of the } \\
\text { results }\end{array}$ & \\
\hline $\begin{array}{l}\text { Duration of } \\
\text { evaluation in } \\
\text { estimation and } \\
\text { valuation } \\
\text { (exploratory) }\end{array}$ & & $\begin{array}{l}\text { Reported in } \\
\text { Appendix A }\end{array}$ & $\begin{array}{l}\text { Explorative, } \\
\text { secondary analysis }\end{array}$ & Not in main text \\
\hline $\begin{array}{l}\text { Confidence } \\
\text { ratings and } \\
\text { deviation in } \\
\text { estimations } \\
\text { (exploratory) }\end{array}$ & & $\begin{array}{l}\text { Multilevel } \\
\text { model. } \\
\text { Reported in } \\
\text { Appendix A }\end{array}$ & $\begin{array}{l}\text { Accounting for the } \\
\text { repeated measures } \\
\text { structure of the data. } \\
\text { Explorative, } \\
\text { secondary analysis }\end{array}$ & $\begin{array}{l}\text { No qualitative } \\
\text { difference. } \\
\text { Not in main text }\end{array}$ \\
\hline $\begin{array}{l}\text { Confidence } \\
\text { ratings in }\end{array}$ & & $\begin{array}{l}\text { Multilevel } \\
\text { model. }\end{array}$ & $\begin{array}{l}\text { Accounting for the } \\
\text { repeated measures }\end{array}$ & $\begin{array}{l}\text { No qualitative } \\
\text { difference. }\end{array}$ \\
\hline $\begin{array}{l}\text { estimations and } \\
\text { lottery variance } \\
\text { (exploratory) }\end{array}$ & & $\begin{array}{l}\text { Reported in } \\
\text { Appendix A }\end{array}$ & $\begin{array}{l}\text { structure of the data. } \\
\text { Explorative, } \\
\text { secondary analysis }\end{array}$ & Not in main text \\
\hline
\end{tabular}

In Experiment 2, we deviated from the preregistration as follows. There was no deviation in the experiment design. Deviations in exclusion criteria include the following: As reported on page 23 , we adjusted the exclusion criterion on the basis of experiment completion time by setting the boundaries (one quarter of the time and 2.5 times the time) on the basis of the actual mean completion time and not the expected completion time (because the actual mean completion time was slightly shorter). Deviations in the analysis are detailed in Table A2. 
Deviations in Analysis, Experiment 2

\begin{tabular}{|c|c|c|c|c|}
\hline Analysis & $\begin{array}{l}\text { Text } \\
\text { page no. }\end{array}$ & Change & Reasoning & Consequence \\
\hline $\begin{array}{l}\text { Influences on } \\
\text { unsystematic } \\
\text { deviation in } \\
\text { estimations and } \\
\text { valuations } \\
\text { (confirmatory) }\end{array}$ & p. 27 & $\begin{array}{l}\text { Not } \\
\text { conducted }\end{array}$ & $\begin{array}{l}\text { The analysis of } \\
\text { unsystematic deviation } \\
\text { is conditional on there } \\
\text { being no systematic } \\
\text { effect (as preregistered } \\
\text { in Experiment 1). } \\
\text { Because there was a } \\
\text { systematic effect, this } \\
\text { analysis cannot } \\
\text { differentiate between } \\
\text { systematic and } \\
\text { unsystematic deviation } \\
\text { and was therefore not } \\
\text { conducted. }\end{array}$ & $\begin{array}{l}\text { Analysis not } \\
\text { possible }\end{array}$ \\
\hline
\end{tabular}

Following are the originally preregistered analyses from Experiment 1.

Complexity aversion in valuations and estimations based on t tests on the lottery level (one-sided, paired). Simple lotteries $(M=98.01, S D=25.46)$ were not valued more highly than complex lotteries $(M=97.57, S D=26.78), B F_{0+}=12.29, t(994)=0.84, p=.20$; analogously, simple lotteries $(M=100.16, S D=23.93)$ were not estimated to have a higher mean than complex lotteries $(M=100.33, S D=25.05), B F_{0+}=37.98, t(1032)=-0.39, p=$ 65 .

Confidence ratings in estimations based on a Wilcoxon test on the lottery level. The test indicated that confidence ratings of simple lotteries $(M d n=5)$ were higher compared to confidence ratings of complex lotteries $(M d n=4), V=176,324, p<.001$. 
Unsystematic deviation in estimations and valuations based on a one-sided $\mathrm{F}$ test of variance (frequentist, as there is no Bayesian equivalent). The test indicated that the mean estimates of simple lotteries $\left(\sigma^{2}=572\right)$ were not significantly less variable than the mean estimates of complex lotteries $\left(\sigma^{2}=628\right), F(1032,1032)=0.91, p=.07$. Analogously, the test for the valuation task indicated that the valuations of simple lotteries $\left(\sigma^{2}=648\right)$ were not significantly less variable than the valuations of complex lotteries $\left(\sigma^{2}=717\right), F(994,994)=$ $0.90, p=.055$.

Exploratory analysis of confidence ratings and deviation in the estimation based on Spearman's rank correlation. Confidence ratings and absolute deviations in the estimation task were negatively correlated, $r_{\mathrm{s}}=-0.20, p<.001$.

Exploratory analysis of confidence ratings in estimation and lottery variance based on Spearman's rank correlation. Confidence ratings and lottery variance in the estimation task were negatively correlated, $r_{\mathrm{s}}=-0.08, p<.001$.

Following are the preregistered exploratory, secondary analyses from Experiment 1, which we did not report in the main text. In addition to the conditional hypothesis, we investigated the relationship of duration and complexity with a one-sided paired sample $t$ test on the aggregated data that revealed inconclusive evidence on whether the mean of simple lotteries $(M=27,848, S D=13,732)$ was estimated in less time than the mean of complex lotteries $(M=30,111, S D=15,628), B F_{-0}=0.68, t(100)=-1.57, p=0.06$. In contrast, in the valuation task, the test revealed that simple lotteries $(M=17,288, S D=8,729)$ were evaluated in considerably less time than complex lotteries $(M=21,900, S D=10,382), B F_{-0}=247,793$, $t(97)=-5.76, p<.001$. Moreover, a cross-comparison of the results suggests that the participants took noticeably more time for the perceptual task than for the preferential task. Furthermore, we investigated the relationship between confidence and the two factors absolute deviation and variance within the lottery. A linear multilevel model was employed instead of the preregistered Spearman correlation to accommodate the repeated-measures 
structure of the data. The results of the Spearman correlation test are consistent with the multilevel analysis and are reported in this appendix (see above). The multilevel model (random intercept for participant id, random slope for each factor) for the relationship between confidence and the log absolute deviation in estimation revealed that the latter was a valid predictor of confidence, $\beta=-0.18,95 \% \mathrm{CI}[-0.23,-0.13]$. This indicates that participants' confidence ratings were moderately related to participants' accuracy. Similarly, the multilevel model (random intercept for participant id, random slope for each factor) for the relationship between confidence and the variance (SD) of the lottery revealed that the latter was a valid predictor of confidence $\beta=-0.0082,95 \%$ CI $[-0.011,-0.0050]$. This indicates that participants' confidence ratings were substantially related to the variance in the presented lotteries. 


\section{Appendix B}

This appendix contains the detailed results of the analysis of the between-subjects factors constant variance or constant range in complex lotteries.

\section{Constant Variance}

We analyzed the data of the 57 participants in the constant variance condition.

Complexity aversion in valuation based on a one-sided, paired $\mathrm{t}$ test on individual aggregated data. The test revealed that participants did value complex lotteries $\left(M_{\mathrm{c}}=96.79\right.$, $\left.S D_{\mathrm{c}}=8.41\right)$ slightly less than simple lotteries $\left(M_{\mathrm{s}}=98.40, S D_{\mathrm{s}}=6.55\right), B F_{-0}=1.25, t(51)=$ $1.78, p=.04$. The Bayes Factor was not substantial though.

Complexity aversion in estimation based on a one-sided, paired $\mathrm{t}$ test on individual aggregated data. The test revealed that participants did not estimate complex lotteries $\left(M_{\mathrm{c}}=\right.$ $\left.99.14, S D_{\mathrm{c}}=7.61\right)$ to have a lower mean than simple lotteries $\left(M_{\mathrm{s}}=98.82, S D_{\mathrm{s}}=6.94\right), B F_{0-}=$ $9.00, t(53)=-0.41, p=.66$.

The influence of complexity, skewness, variance, and expected value on estimation based on a Bayesian multilevel model. The results of this analysis are shown in Table B1.

\section{Table B1}

Beta Estimates of Estimations and 95\% Confidence Intervals for Constant Variance

\begin{tabular}{lllll}
\hline Factor & Estimate $(\beta)$ & Estimation & \multicolumn{2}{c}{$95 \%$ CI } \\
\cline { 4 - 5 } & & error & $L L$ & $U L$ \\
\hline Intercept & 0.76 & 1.50 & -2.20 & 3.75 \\
Complexity & 0.20 & 0.75 & -1.27 & 1.68 \\
Skewness & 0.79 & 0.50 & -0.19 & 1.77 \\
SD & 0.02 & 0.02 & -0.02 & 0.06 \\
EV & $0.97^{\text {a }}$ & 0.01 & 0.94 & 1.00
\end{tabular}

Note. Complexity: Simple $=0$ and complex $=1 ; \mathrm{SD}=$ standard deviation; $\mathrm{EV}=$ expected value; estimation $=$ corresponding mean estimate LL $=$ lower limit; $\mathrm{UL}=$ upper limit.

${ }^{\text {a }}$ Indicates a beta estimate for which zero is not contained in the credible interval. 
Influence of complexity, skewness, variance and expected value on valuation based on a Bayesian multilevel model. The results of this analysis are shown in Table B2.

\section{Table B2}

Beta Estimates of Valuation and 95\% Confidence Intervals for Constant Variance

\begin{tabular}{lllll}
\hline Factor & \multirow{2}{*}{ Estimate $(\beta)$} & Estimation & \multicolumn{2}{c}{$95 \% \mathrm{CI}$} \\
\cline { 4 - 5 } & & error & $L L$ & $U L$ \\
\hline Intercept & 3.01 & 1.90 & -0.70 & 6.76 \\
Complexity & -1.19 & 0.90 & -2.98 & 0.57 \\
Skewness & $2.34^{\mathrm{a}}$ & 0.67 & 1.02 & 3.67 \\
SD & $-0.13^{\mathrm{a}}$ & 0.05 & -0.23 & -0.04 \\
EV & $0.97^{\mathrm{a}}$ & 0.02 & 0.93 & 1.00
\end{tabular}

Note. Complexity: Simple $=0$ and complex $=1 ; \mathrm{SD}=$ standard deviation; $\mathrm{EV}=$ expected value; estimation $=$ corresponding mean estimate $; \mathrm{LL}=$ lower limit $\mathrm{UL}=$ upper limit.

${ }^{\text {a }}$ Indicates a beta estimate for which zero is not contained in the credible interval.

Influence of matched estimation on valuation based on a Bayesian multilevel model. The results of this analysis are shown in Table B3.

\section{Table B3}

Valuation and Estimation (including Confidence Intervals) for Constant Variance

\begin{tabular}{lllcc}
\hline Factor & Estimate $(\beta)$ & Estimation & \multicolumn{2}{c}{$95 \% \mathrm{CI}$} \\
\cline { 4 - 5 } & & error & $L L$ & $U L$ \\
\hline Estimation & $0.82^{\mathrm{a}}$ & 0.02 & 0.78 & 0.87
\end{tabular}

Note . Estimation $=$ Corresponding mean estimate; $\mathrm{LL}=$ lower limit; $\mathrm{UL}=$ upper limit.

${ }^{\text {a }}$ Indicates a beta estimate for which zero is not contained in the credible interval. 
Confidence ratings in estimation were analyzed with a paired Wilcoxon test on individual aggregated data. The participants indicated higher confidence for their estimates of simple lotteries $\left(M d n_{\mathrm{s}}=4.6\right)$ compared to complex lotteries $\left(M d n_{\mathrm{c}}=3.6\right), V=1,253, p<.001$.

\section{Constant Range}

We analyzed the data of the 51 participants in the constant range condition.

Complexity aversion in valuation based on a one-sided, paired $\mathrm{t}$ test on individual aggregated data. The test revealed that participants did not value complex lotteries $\left(M_{\mathrm{c}}=\right.$ 98.69, $\left.S D_{\mathrm{c}}=9.67\right)$ less than simple lotteries $\left(M_{\mathrm{s}}=97.95, S D_{\mathrm{s}}=10.44\right), B F_{0-}=9.40, t(45)=-$ $0.60, p=.73$

Complexity aversion in estimation based on a one-sided, paired $\mathrm{t}$ test on individual aggregated data. The test revealed that participants did not estimate complex lotteries $\left(M_{\mathrm{c}}=\right.$ 101.22, $\left.S D_{\mathrm{c}}=6.05\right)$ to have a lower mean than simple lotteries $\left(M_{\mathrm{s}}=101.31, S D_{\mathrm{s}}=4.77\right)$, $B F_{0-}=5.65, t(50)=0.14, p=.45$.

Influence of complexity, skewness, variance, and expected value on estimation based on a Bayesian multilevel model. The results of this analysis are shown in Table B4.

\section{Table B4}

Beta Estimates of Estimations and 95\% Confidence Intervals for Constant Range

\begin{tabular}{lllcc}
\hline Factor & Estimate $(\beta)$ & Estimation & \multicolumn{2}{c}{$95 \%$ CI } \\
\cline { 4 - 5 } & & error & $L L$ & $U L$ \\
\hline Intercept & 0.01 & 1.45 & -2.83 & 2.85 \\
Complexity & -0.05 & 0.66 & -1.36 & 1.25 \\
Skewness & $1.62^{\mathrm{a}}$ & 0.37 & 0.89 & 2.36 \\
SD & 0.004 & 0.03 & -0.05 & 0.05 \\
EV & $0.99^{\mathrm{a}}$ & 0.01 & 0.96 & 1.01
\end{tabular}

Note. Complexity: Simple $=0$ and complex $=1 ; \mathrm{SD}=$ standard deviation; $\mathrm{EV}=$ expected value; $\mathrm{LL}=$ lower limit; $\mathrm{UL}=$ upper limit.

${ }^{a}$ indicates a $\beta$ estimate for which zero is not contained in the credible interval. 
Influence of complexity, skewness, variance, and expected value on valuation based on a Bayesian multilevel model. The results of this analysis are shown in Table B5.

\section{Table B5}

Beta Estimates of Valuation and 95\% Confidence Intervals for Constant Range

\begin{tabular}{lllcc}
\hline Factor & \multirow{2}{*}{ Estimate $(\beta)$} & Estimation & \multicolumn{2}{c}{$95 \%$ CI } \\
\cline { 4 - 5 } & & error & $L L$ & $U L$ \\
\hline Intercept & 0.90 & 1.67 & -2.37 & 4.16 \\
Complexity & -0.57 & 0.88 & -2.27 & 1.17 \\
Skewness & $2.95^{\text {a }}$ & 0.54 & 1.89 & 4.01 \\
SD & $-0.14^{\text {a }}$ & 0.05 & -0.24 & -0.04 \\
EV & $0.99^{\text {a }}$ & 0.02 & 0.96 & 1.02
\end{tabular}

Note. Complexity: Simple $=0$ and complex $=1 ; \mathrm{SD}=$ standard deviation; $\mathrm{EV}=$ expected value; $\mathrm{LL}=$ lower limit; $\mathrm{UL}=$ upper limit.

${ }^{\mathrm{a}}$ Indicates a beta estimate for which zero is not contained in the credible interval.

Influence of matched estimation on valuation based on a Bayesian multilevel model.

The results of this analysis are shown in Table B6.

\section{Table B6}

Valuation and Estimation (Including Confidence Intervals) for Constant Range

\begin{tabular}{llllc}
\hline Factor & Estimate $(\beta)$ & Estimation & \multicolumn{2}{c}{$95 \%$ CI } \\
\cline { 3 - 5 } & & error & $L L$ & $U L$ \\
\hline Estimation & $0.85^{\mathrm{a}}$ & 0.02 & 0.80 & 0.89 \\
\hline
\end{tabular}

Note . Estimation $=$ Corresponding mean estimate; $\mathrm{LL}=$ lower limit; $\mathrm{UL}=$ upper limit.

${ }^{\text {a }}$ Indicates a beta estimate for which zero is not contained in the credible interval.

Confidence ratings in estimation were analyzed with a paired Wilcoxon test on individual aggregated data. The participants indicated higher confidence for their estimates of simple lotteries $\left(M d n_{\mathrm{s}}=4.9\right)$ compared to complex lotteries $\left(M d n_{\mathrm{c}}=4.0\right), V=923, p<.001$. 


\section{Appendix C}

Following is additional information for Experiment 2. The power calculation for the sample size was based on a hypothetical $t$ test comparing the choice proportions on an individual level against $\mu=0.5$ (null effect). For the simulation, we increased the standard deviation $(0.25)$ of the individual choice proportions found in the pilot by $15 \%$ to accommodate a possible increase in data noise. Additionally, we reduced the difference $(15.2 \%)$ on the basis of which the statistical test was conducted by $15 \%$, to accommodate a possible decrease in effect size. This simulation revealed a BF larger than 10, supporting the alternative in $99.9 \%$ of the cases, indicating sufficiently high power. Figure D1 is an alternative graph depicting the interaction between expected value sensitivity and cognitive ability in Experiment 2.

\section{Figure D1}

Interaction Plot for Cognitive Ability and Expected Value Sensitivity in Choice

A



B

Simple Option Right Side

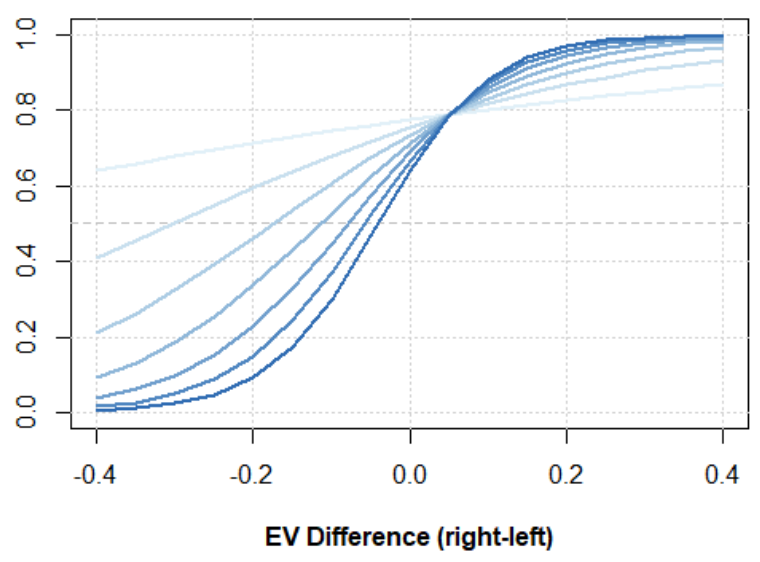

Note. Higher cognitive ability leads to more expected value (EV) sensitivity. The difference between Panels A and B illustrates that the complex option is less likely to be chosen. EV differences in the experiment ranged between -0.15 and 0.15 . The $x$ axis of the plot was extended to -0.4 and 0.4 to increase clarity and visibility. 